\title{
Leptin Regulates AMPA Receptor Trafficking via PTEN Inhibition
}

\author{
Peter R. Moult, ${ }^{1}$ Alasdair Cross, ${ }^{1}$ Sandra D. Santos, ${ }^{3}$ Ana-Luisa Carvalho, ${ }^{3}$ Yvonne Lindsay, ${ }^{2}$ Christopher N. Connolly, ${ }^{1}$ \\ Andrew J. Irving, ${ }^{1}$ Nicholas R. Leslie, ${ }^{2}$ and Jenni Harvey ${ }^{1}$ \\ ${ }^{1}$ Centre for Neuroscience, Division of Medical Sciences, Ninewells Hospital, and 2Department of Molecular Physiology, University of Dundee, Dundee DD1 \\ 9SY, United Kingdom, and ${ }^{3}$ Center for Neuroscience, Department of Zoology, University of Coimbra, 3004-504 Coimbra, Portugal
}

The hormone leptin can cross the blood- brain barrier and influences numerous brain functions (Harvey, 2007). Indeed, recent studies have demonstrated that leptin regulates activity-dependent synaptic plasticity in the CA1 region of the hippocampus (Shanley et al., 2001; Li et al., 2002; Durakoglugil et al., 2005; Moult et al., 2009). It is well documented that trafficking of AMPA receptors is pivotal for hippocampal synaptic plasticity (Collingridge et al., 2004), but there is limited knowledge of how hormonal systems like leptin influence this process. In this study we have examined how leptin influences AMPA receptor trafficking and in turn how this impacts on excitatory synaptic function. Here we show that leptin preferentially increases the cell surface expression of GluR1 and the synaptic density of GluR2-lacking AMPA receptors in adult hippocampal slices. The leptin-induced increase in surface GluR1 required NMDA receptor activation and was associated with an increase in cytoplasmic PtdIns $(3,4,5) \mathrm{P}_{3}$ levels. In addition, leptin enhanced phosphorylation of the lipid phosphatase PTEN which inhibits PTEN function and elevates PtdIns $(3,4,5) \mathrm{P}_{3}$ levels. Moreover, inhibition of PTEN mimicked and occluded the effects of leptin on GluR1 trafficking and excitatory synaptic strength. These data indicate that leptin, via a novel pathway involving PTEN inhibition, promotes GluR1 trafficking to hippocampal synapses. This process has important implications for the role of leptin in hippocampal synaptic function in health and disease.

\section{Introduction}

Glutamate is the main excitatory neurotransmitter in the mammalian CNS, and a key feature of neuronal networks is the ability to dynamically alter excitatory synaptic strength. Indeed, hippocampal synaptic plasticity is thought to underlie learning and memory (Bliss and Collingridge, 1993). AMPA receptor trafficking is pivotal for rapid forms of hippocampal synaptic plasticity (Collingridge et al., 2004) such as long-term potentiation (LTP) and long-term depression (LTD). However, little is known about how such events are regulated by hormones or altered in pathological states. Recent studies have shown that tumor necrosis factor- $\alpha$ (TNF- $\alpha)$ increases AMPA receptor surface expression (Stellwagen and Malenka, 2006), which may contribute to its role in mediating brain damage from pathological insults. Insulin also alters AMPA receptor trafficking and synaptic function (Passafaro et al., 2001; Zhou et al., 2001), and defects in insulin-driven processes are linked to neurodegenerative disorders such as Alzheimer disease.

AMPA receptor trafficking is dependent on phosphoinositide 3-kinase (PI 3-kinase; Man et al., 2003), an ubiquitous enzyme that promotes phosphorylation of $\operatorname{PtdIns}(4,5) \mathrm{P}_{2}$ to generate PtdIns $(3,4,5) \mathrm{P}_{3}$ (Cantley, 2002). Thus, PI 3-kinase-driven elevations in PtdIns $(3,4,5) \mathrm{P}_{3}$ may contribute to alterations in AMPA

\footnotetext{
Received July 27, 2009; revised Jan. 14, 2010; accepted Jan. 19, 2010.

This work was supported by the Wellcome Trust (075821), Medical Research Scotland, and The Royal Society. We thank Karen-Ann Bollan and Hemanth Tummala for their valuable help with the biotinylation studies.

Correspondence should be addressed to Dr. Jenni Harvey at the above address. E-mail:j.z.harvey@dundee.ac.uk. DOI:10.1523/JNEUROSCI.3614-09.2010

Copyright $\odot 2010$ the authors $\quad 0270-6474 / 10 / 304088-14 \$ 15.00 / 0$
}

receptor trafficking. The tumor suppressor PTEN (phosphatase and tensin homolog deleted on chromosome 10) limits PI 3-kinase-dependent signaling by dephosphorylating $\operatorname{PtdIns}(3,4,5) \mathrm{P}_{3}$ into PtdIns (4,5) $\mathrm{P}_{2}$ (Maehama and Dixon, 1998). PTEN contains a tyrosine phosphatase functional domain, exhibiting both protein phosphatase and lipid phosphatase activity in vitro. In most cells, PTEN is constitutively active and influences the basal levels of PtdIns $(3,4,5) \mathrm{P}_{3}$. However, inhibition of PTEN activity by reactive oxygen species and phosphorylation leads to modified PI 3-kinase-dependent signaling (Downes et al., 2007). In pancreatic $\beta$ cells and a hypothalamic cell line the hormone leptin also promotes phosphorylation of PTEN, resulting in inhibition of PTEN activity and an increase in $\operatorname{PtdIns}(3,4,5) \mathrm{P}_{3}$ levels (Ning et al., 2006).

Evidence is growing that leptin influences numerous neuronal functions (Harvey, 2007). Leptin regulates energy homeostasis via its hypothalamic actions (Spiegelman and Flier, 2001). Recent studies have implicated leptin in hippocampal synaptic plasticity as leptin-insensitive rodents display impaired LTP and LTD and spatial memory (Li et al., 2002). Administration of leptin into rodent hippocampus improves memory processing (Wayner et al., 2004). Moreover, leptin facilitates LTP (Shanley et al., 2001) and evokes NMDA receptor-dependent LTD (Durakoglugil et al., 2005). However, it is not known whether leptin influences AMPA receptor trafficking and in turn how this impacts on excitatory synaptic function. Here we provide the first compelling evidence that leptin rapidly increases GluR1 surface expression and promotes an increase in the synaptic expression of GluR2lacking AMPA receptors in adult hippocampus. The increase in 
GluR1 trafficking by leptin is associated with an increase in PtdIns $(3,4,5) \mathrm{P}_{3}$ levels. This is accompanied by increased phosphorylation of PTEN, an action resulting in PTEN inactivation and increased PtdIns $(3,4,5) \mathrm{P}_{3}$ levels. Indeed, PTEN inhibition mimicked and occluded the effects of leptin on GluR1 trafficking to synapses, indicating the involvement of PTEN inhibition. These findings have important implications for the role of leptin and PTEN in regulating hippocampal synaptic strength.

\section{Materials and Methods}

Hippocampal cell culture. Hippocampal cultures were prepared as before (Shanley et al., 2001). Briefly, neonatal Sprague-Dawley rats (1-3 d old) were killed by cervical dislocation in accordance with Schedule 1 of UK Animals (Scientific Procedures) Act, 1986. Hippocampi were removed and after washing in HEPES buffered saline containing the following (in mM): $135 \mathrm{NaCl} ; 5 \mathrm{KCl} ; 1 \mathrm{CaCl}_{2} ; 1 \mathrm{MgCl}_{2} ; 10$ HEPES; 25 D-glucose, $\mathrm{pH} 7.4$, were treated with protease type X and type XIV $(0.5 \mathrm{mg} / \mathrm{ml}$; Sigma) for $25 \mathrm{~min}$ at room temperature. Dissociated cells were plated onto sterile dishes (Falcon 3001$)$ treated with poly-L-lysine (20 $\mu \mathrm{gml}-1$; $1-2 \mathrm{~h})$. Cultures were maintained in serum replacement medium (SR2; Sigma) in a humidified atmosphere of $5 \% \mathrm{CO}_{2}$ and $95 \% \mathrm{O}_{2}$ at $37^{\circ} \mathrm{C}$ for up to 3 weeks.

Transfection protocol. Cells were transfected with PTEN C124S or PTEN G129E in EGFP-C2 or empty vector, EGFP-C2, using lipofectamine 2000 (L2K). L2K was mixed with MEM (ratio of $3 \mu$ L L2K: 100 $\mu \mathrm{l}$ MEM), and the desired plasmid was mixed with Optimem (ratio of 2 $\mu \mathrm{g}$ plasmid: $100 \mu \mathrm{l}$ Optimem. After $5 \mathrm{~min}$ the diluted L2K and plasmid were mixed and left at room temperature for $20 \mathrm{~min}$. $200 \mu \mathrm{l} 2 \mathrm{~K}+\mathrm{DNA}$ mix was added to each coverslip of neurons (6-10 DIV) in $1 \mathrm{ml}$ of culture media. Cells were returned to the incubator for $1 \mathrm{~h}$, before washing. Transfected cells were used $24-48 \mathrm{~h}$ after transfection.

Immunocytochemistry and analysis. Immunocytochemistry was performed on 7- to 12-d-old cultured hippocampal neurons after treatment with vehicle or leptin $(50 \mathrm{~nm})$ for $30 \mathrm{~min}$ at $21-23^{\circ} \mathrm{C}$. To label surface GluR1 or GluR2, living neurons were incubated with antibodies against N-terminal regions of GluR1 (sheep anti-GluR1; in house antibody against synthetic peptide (RTSDSRDHTRVDWKR) corresponding to 253-267 residues of GluR1; Pickard et al., 2001; 1:100) and GluR2 (mouse anti-GluR2; Zymed; 1:250) at $4^{\circ} \mathrm{C}$. Cultures were fixed with $4 \%$ paraformaldehyde (10 min) which did not permeabilize cells as assayed by the absence of microtubule-associated protein 2 (MAP2) staining. Surface GluR1 or GluR2 staining was visualized by addition of appropriate Alexa 488- or Cy3-conjugated secondary antibodies (1:250; Stratech Scientific, UK) for $30 \mathrm{~min}$. No labeling was observed after incubation with secondary antibodies alone. In some studies, cells were permeabilized with $0.1 \%$ Triton $\mathrm{X}-100(5 \mathrm{~min})$ to compare staining relative to synapsin-1 (mouse anti-synapsin-1; 1:250; 30 min; BD Biosciences), PTEN (mouse anti-PTEN; 1:500; $30 \mathrm{~min}$; Cascade Biosciences) or PtdIns $(3,4,5) \mathrm{P}_{3}$ (mouse PtdIns $(3,4,5) \mathrm{P}_{3} ; 1: 500 ; 1 \mathrm{~h}$; Echelon) labeling. For synaptic colocalization, surface GluR1 staining was compared with synapsin-1 and percentage of surface GluR1 at synapses was assessed as number of GluR1-positive sites that colocalized with synapsin-1-positive sites.

For global PTEN immunolabeling, neurons were fixed, washed with HEPES-buffered saline (HBS), and then permeabilized. Neurons were treated with primary antibody (mouse anti-PTEN; clone 6H2.1; 1:500) for $30 \mathrm{~min}$ at room temperature. After washing, neurons were incubated with donkey anti-mouse antibody (1:250; $30 \mathrm{~min})$. In dual labeling studies, the anti-GluR1 antibody (above) was used to assess distribution at somato-dendritic regions or antibody against an $\mathrm{N}$-terminal epitope of CB1 receptor (gift from K. Mackie, Indiana University, Bloomington, IN; 1:100; 1 h; Coutts et al., 2001) to determine PTEN distribution on axons. Living neurons were incubated with either of these antibodies before fixation and incubation with a secondary antibody. PTEN distribution was examined after neurons were permeabilized.

For P366-PTEN or P385-PTEN immunostaining, neurons were fixed, permeabilized, and then incubated with a sheep anti-P366 PTEN antibody (1:500; Maccario et al., 2007) or rabbit anti-P385 PTEN antibody
(1:500; Biosource) for $30 \mathrm{~min}$. In dual labeling studies, markers for endosomes (mouse anti-RAB5; 1:500; or rabbit anti-RAB7; 1:500; Sigma), the Golgi apparatus (mouse anti-mannosidase II; 1:1000; Covance), P385 PTEN (rabbit anti-P385 PTEN; 1:500; Biosource), or PtdIns $(3,4,5) \mathrm{P}_{3}$ (above) were used.

Analysis. A confocal imaging system (Zeiss LSM 510) was used for image acquisition. Laser lines ( 488 and $543 \mathrm{~nm}$ ) were used to excite Alexa 488 and Cy3 fluorophores, respectively. Dual labeling images were obtained in multitracking mode using a $15 \mathrm{~s}$ scan speed. Intensity of staining was determined off-line using Lasersharp software (Carl Zeiss). Analysis lines $(50 \mu \mathrm{m})$ were drawn along randomly selected dendritic regions (50 $\mathrm{nm}$ ), and mean fluorescence intensity was calculated. Data were obtained from at least three randomly selected cells for each condition, and all data were obtained from at least three different cultures from different animals. Within a given experiment, all conditions, including illumination intensity and photomultiplier gains, were kept constant. To quantify experimental data obtained from separate days, data were normalized relative to mean fluorescence intensity in control neurons. In a subset of control experiments indicated in the text, both surface and total GluR1 were labeled and changes in surface GluR1 calculated as a function of total GluR1. All data are expressed as means \pm SEM, and statistical analyses were performed using Student's unpaired $t$ test for comparison of means, or ANOVA for comparisons between multiple groups. $p<$ 0.05 was considered significant.

Hippocampal slice preparation and electrophysiology. Hippocampal slices $(350 \mu \mathrm{m})$ were prepared from 12- to 16-week-old male, SpragueDawley rats or Zucker lean or $f a / f a$ rats. Animals were killed by cervical dislocation according to UK (Scientific Procedures) legislation. Brains were rapidly removed and placed in ice-cold artificial CSF (aCSF; bubbled with $95 \% \mathrm{O}_{2}$ and $5 \% \mathrm{CO}_{2}$ ) containing the following (in mM): 124 $\mathrm{NaCl}, 3 \mathrm{KCl}, 26 \mathrm{NaHCO}_{3}, 1.25 \mathrm{NaH}_{2} \mathrm{PO}_{4}, 2 \mathrm{CaCl}_{2}, 1 \mathrm{MgSO}_{4}$, and 10 $\mathrm{D}$-glucose. Once prepared, parasagittal slices were allowed to recover at room temperature in oxygenated aCSF for $1 \mathrm{~h}$ before use. Slices were transferred to a submerged chamber maintained at $30-31^{\circ} \mathrm{C}$ and perfused with aCSF containing the $\mathrm{GABA}_{\mathrm{A}}$ receptor antagonist, picrotoxin $(50 \mu \mathrm{M})$, at a rate of 2-3 $\mathrm{ml} \cdot \mathrm{min}^{-1}$. Blind whole-cell recordings from stratum pyramidale of area CA1 were obtained using electrodes $(4-7 \mathrm{M} \Omega$ ) containing the following (in $\mathrm{mm}): 130 \mathrm{Cs}^{+}$methanesulphonate, $5 \mathrm{NaCl}, 1 \mathrm{CaCl}_{2}, 5 \mathrm{HEPES}, 1 \mathrm{EGTA}, 5$ Mg-ATP, 0.5 Na-GTP, and 5 QX-314, pH 7.3. Where 10 mM BAPTA was included in the filling solution, EGTA was absent and the concentration of $\mathrm{Cs}^{+}$methanesulphonate adjusted to maintain osmolarity. Unless otherwise stated cells were voltage clamped at $-60 \mathrm{mV}$. The Schaffer collateralcommissural pathway was stimulated at $0.033 \mathrm{~Hz}$, using a stimulus intensity that evoked a peak amplitude $\sim 50 \%$ of the maximum. Synaptic currents were low pass filtered at $2 \mathrm{kHz}$ and digitally sampled at $10 \mathrm{kHz}$. The mean series resistance for all cells was $23 \pm 3 \mathrm{M} \Omega(n=112)$.

Data were monitored online and analyzed off-line using the WINltp program (Anderson and Collingridge, 2007). The degree of potentiation was calculated $40-45 \mathrm{~min}$ after addition of leptin or bpV and expressed as a percentage of baseline. The paired pulse ratio (PPR) was calculated as ratio of amplitude of second EPSC to first EPSC. To ensure measurement of second EPSC was not contaminated, the residual component of first EPSC was removed (Moult et al., 2009). The coefficient of variation (CV) was calculated as before (Moult et al., 2009). Briefly, the mean and SD were calculated for EPSC amplitudes recorded during successive $5 \mathrm{~min}$ epochs $\left(\mathrm{SD}_{\mathrm{EPSC}}\right.$ and mean $\left.\mathrm{EPSC}_{\mathrm{ES}}\right)$. The $\mathrm{SD}$ of background noise was calculated for each 5 min epoch using a period immediately before electrical stimulation $\left(\mathrm{SD}_{\text {noise }}\right)$. The $\mathrm{CV}$ for each 5 min epoch was calculated as $\left(\mathrm{SD}_{\text {EPSC }}-\mathrm{SD}_{\text {noise }}\right) /$ mean $_{\text {EPSC }}$. For calculation of RI, $0.1 \mathrm{~mm}$ spermine was included in the pipette solution. Cells were depolarized to +40 $\mathrm{mV}$ for $2 \mathrm{~min}$ (four successive stimulations) before leptin or bpV application, and this was repeated at the peak of their effects. The rectification index (RI) was calculated as the ratio of the initial slopes of the EPSCs: EPSC $_{\text {hyperpolarised }} /$ EPSC $_{\text {depolarized }}$.

Whole-cell recordings from hippocampal cultures. Whole-cell recordings from pyramidal neurons were obtained as previously detailed. Cells were voltage clamped at $-60 \mathrm{mV}$ using the same intracellular solutions used for recording from hippocampal slices. Cells were perfused continuously with $\mathrm{HBS}$ of the following composition (in $\mathrm{mm}$ ): $119 \mathrm{NaCl}, 5 \mathrm{KCl}$, 
$2 \mathrm{CaCl}_{2}, 2 \mathrm{MgCl}_{2}, 25$ HEPES, 33 D-glucose, 0.005 tetrodotoxin citrate, 0.1 picrotoxin, and 0.001 glycine, $\mathrm{pH} 7.4$, at a rate of $2-3 \mathrm{ml} \cdot \mathrm{min}^{-1}$. Leptin was applied by addition to the HBS perfusate. Data were filtered at $2 \mathrm{kHz}$ and digitized at $10 \mathrm{kHz}$. Continuous recording of miniature EPSCs (mEPSCs) was made using the WinLTP program (Anderson and Collingridge, 2007). mEPSC detection was performed using MiniAnalysis software (Synaptosoft). Events were detected by setting the threshold value for detection at three times the level of the root mean square noise, followed by visual confirmation of mEPSC detection. For construction of cumulative probability plots, 400 successive events were used from the period immediately preceding application of leptin and from the period before $20 \mathrm{~min}$ after commencing washout of leptin. For pooled cumulative probability plots, data were normalized to the median value in the preleptin period.

Western blotting for P366 experiments. Samples were processed for Western blotting as previously described (Maccario et al., 2007). Briefly, after exposure of slices to either leptin or control media, slices were homogenized in ice-cold lysis buffer consisting of $25 \mathrm{~mm}$ HEPES, $150 \mathrm{~mm}$ $\mathrm{NaCl}, 1 \%$ Triton X-100, 0.1\% 2 mercaptoethanol, 1 mм EDTA, 1 mм EGTA, $10 \mathrm{~mm} \beta$ glycerophosphatase, $50 \mathrm{~mm}$ sodium fluoride, $10 \mu \mathrm{g} / \mathrm{ml}$ leupeptin, $100 \mu \mathrm{M}$ PMSF, and $1 \mathrm{~mm}$ benzamidine. Proteins were separated by PAGE using precast $4-12 \%$ gradient gels and blotted onto polyvinylidene difluoride (PVDF) membranes (Polyscreen: NEN/PerkinElmer). Immunoprecipitation of PTEN used the A2B1 monoclonal antibody (Santa Cruz Biotechnology), preconjugated with agarose beads. Immunoprecipitation of P366 PTEN used the phospho-specific antibody against PTEN phosphor-Thr ${ }^{366}$ synthesized by Dr. Graham Bloomberg (Molecular Recognition Centre, University of Bristol, Bristol, UK). Quantification was made using AIDA image analysis software. Each experiment was done in triplicate, and data were normalized to control values within each experiment and then expressed as mean percentage of normalized control $\pm \mathrm{SE}$ of mean.

Cell surface protein biotinylation in hippocampal slices. Hippocampal slices $(350 \mu \mathrm{m})$ obtained from Sprague-Dawley rats 3-4 weeks old and 13-16 weeks old and Zucker lean and $f a / f a$ rats (13-16 weeks old) were used (Thomas-Crusells et al., 2003). Zucker $f a / f a$ rats contain a mutation ( $f a$ mutation) in the extracellular region of the leptin receptor, resulting in resistance to exogenous administration of leptin. Slices (three slices per condition) were incubated for $15 \mathrm{~min}$ at $37^{\circ} \mathrm{C}$ in aCSF (control condition), or $25 \mathrm{~nm}$ leptin and $50 \mu \mathrm{m}$ picrotoxin in aCSF, under continuous gasification with $95 \% \mathrm{O}_{2}$ and $5 \% \mathrm{CO}_{2}$. Slices were transferred to aCSF solution containing $0.3 \mathrm{mg} / \mathrm{ml}$ NHS-SS-biotin (Pierce) and kept on ice with agitation for $45 \mathrm{~min}$. Slices were then incubated in aCSF with $1 \mu \mathrm{M}$ lysine to block all reactive NHS-SS-biotin in excess. Slices were then collected in $500 \mu \mathrm{l}$ of lysis buffer (1\% Triton X-100, 0.1\% SDS, $1 \mathrm{~mm}$ EDTA, $50 \mathrm{~mm} \mathrm{NaCl}, 20$ mм Tris, pH 7.5, supplemented with 1 mм DTT and a mixture of protease inhibitors- $0.1 \mathrm{mM}$ PMSF; $1 \mu \mathrm{g} / \mathrm{ml}$ chymostatin, $1 \mu \mathrm{g} / \mathrm{ml}$ leupeptin, $1 \mu \mathrm{g} / \mathrm{ml}$ antipain, $1 \mu \mathrm{g} / \mathrm{ml}$ pepstatin) and sonicated on ice for $30 \mathrm{~s}$. To discard extra debris, homogenates were centrifuged for $5 \mathrm{~min}$ at $4^{\circ} \mathrm{C}$ at 13,000 rpm and supernatants collected. Protein concentration was quantified by the BCA method (Pierce), and the same amount of protein $(500-750 \mu \mathrm{g})$ was used in all experimental conditions. To precipitate biotinylated proteins, $40 \mu \mathrm{l}$ of Ultra-link immobilized neutravidin plus beads were added to samples for $2 \mathrm{~h}$ at $4^{\circ} \mathrm{C}$, under constant agitation. Nonbiotinylated proteins were removed by centrifugation at $2500 \times g$ for $2 \mathrm{~min}$, and beads were washed three times with lysis buffer. Biotinylated proteins were eluted with denaturing buffer at $95^{\circ} \mathrm{C}$ for $5 \mathrm{~min}$. Samples were processed for Western blotting analysis with the sheep anti-GluR1 antibody (1:750) or rabbit anti-GluR2 antibody (1:600). Alkaline phosphatase-conjugated secondary antibodies were used, and alkaline phosphatase activity was visualized by enhanced chemifluorescence (ECF) on Storm $860 \mathrm{Gel}$ and Blot Imaging System (GE Healthcare). Scanned digital images were quantified using ImageQuant 5 software (GE Healthcare). Results are presented as means \pm SEM of number of experiments performed in different preparations. Statistical significance was determined by the Student $t$ test $\left({ }^{*} p<0.05\right)$.

Materials. Recombinant human leptin (R\&D Systems Europe) was used in all experiments. LY294002, wortmannin, bisperoxovanadium
(Calbiochem), and D-AP5 (Tocris Cookson) were all obtained commercially.

Statistical analyses. All data are expressed as means \pm SEM, and statistical analyses were performed using paired $t$ test (two-tailed; 95\% confidence interval) for comparison of means or two-way ANOVA (ANOVA) with Tukey post hoc test for comparisons between multiple groups (unless otherwise stated). $p<0.05$ was considered significant.

\section{Results}

\section{Leptin differentially regulates the surface expression of GluR1 and GluR2}

To determine whether leptin alters the density of AMPA receptors, the cell surface expression of AMPA receptors was assayed using an N-terminal antibody against GluR1 on living hippocampal neurons (Fig. $1 A, B)$. Leptin ( $50 \mathrm{~nm} ; 30 \mathrm{~min}$ ) induced a robust increase $(154 \pm 4.9 \%$ of untreated cultures; $n=78 ; p<0.01)$ in GluR1 surface expression. This effect was due to leptin as application of the inactive boiled peptide failed to alter GluR1 surface staining $(103 \pm 1.2 \%$ of control; $n=9 ; p>0.05)$.

In hippocampal pyramidal cells, endogenous AMPA receptors consist of GluR1 and GluR2 subunits. To examine whether leptin influenced GluR2 surface expression, dual labeling approaches were used to compare the effects of leptin on GluR1 versus GluR2. Leptin (1-50 nM; $30 \mathrm{~min}$ ) produced a concentration-dependent increase in GluR1 surface staining (Fig. 1B). Thus, $1 \mathrm{~nm}$ leptin increased surface GluR1 staining to $115 \pm 5.1 \%$ of control $(n=27 ; p<0.05)$ whereas $50 \mathrm{~nm}$ leptin resulted in an increase to $144 \pm 5.7 \%(n=34 ; p<0.01)$. In contrast, leptin was less potent at altering GluR2 surface expression (Fig. $1 B$ ). At $1 \mathrm{nM}$ $(106 \pm 3.6 \%$ of control; $n=27 ; p>0.05)$ and $10 \mathrm{~nm}(109 \pm$ $4.0 \% ; n=29 ; p>0.05)$, leptin failed to evoke a significant change in surface GluR2 staining, however at higher concentrations, leptin increased GluR2 staining to $121 \pm 5.4 \%$ of control $(n=37$; $p<0.01)$.

\section{Leptin increases the density of GluR1 subunits at hippocampal synapses}

As the circulating leptin levels are in the low nanomolar range (Caro et al., 1996), the GluR1 subunit is likely to be the main target for leptin under physiological conditions. As the surface expression of receptors is a balance between exocytotic and endocytotic mechanisms, the increase in surface GluR1 expression by leptin could be due to alterations in either process. To determine whether leptin alters GluR1 exocytosis, we examined the effects of two inhibitors namely NEM, a broad spectrum inhibitor of $N$-ethylmaleimide-sensitive fusion protein (NSF) and brefeldin A (Fig. 1C). Application of NEM ( 5 mM; 40 min; $n=27$ ) or brefeldin A ( $5 \mu \mathrm{M} ; 40 \mathrm{~min} ; n=27)$ had no significant effect on GluR1 surface expression per se. However, prior exposure to either agent attenuated the effects of leptin as the increase in GluR1 surface staining induced by leptin (to $141 \pm 4 \% ; n=27)$ was reduced to $104 \pm 6 \%$ of control $(n=$ $27 ; p>0.05)$ and $113 \pm 5 \%$ of control $(n=27 ; p>0.05)$ in the presence of NEM or brefeldin A, respectively. These data indicate that leptin increases GluR1 surface density by promoting GluR1 exocytosis.

The strength of excitatory synaptic transmission is dependent on the density of AMPA receptors expressed at synapses. To assess whether leptin influences the synaptic localization of GluR1, we compared the distribution of surface GluR1 relative to synapses (anti-synapsin-1 antibody) using immunocytochemistry, and the percentage colocalization was evaluated. In accordance with our previous findings (O'Malley et al., 2007), leptin in- 
A
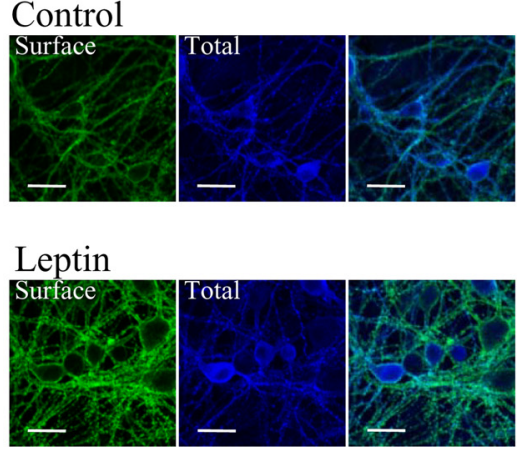

C

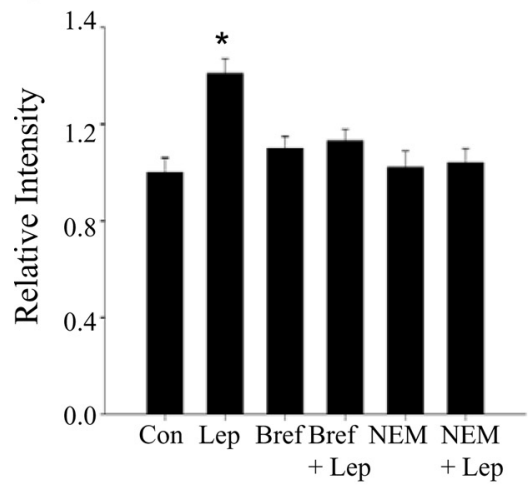

$\mathrm{Ei}$

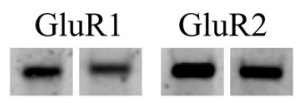

3-4 week

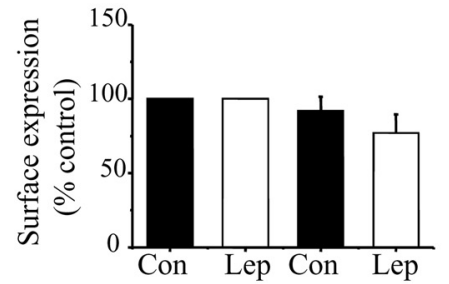

$\mathrm{Fi}$
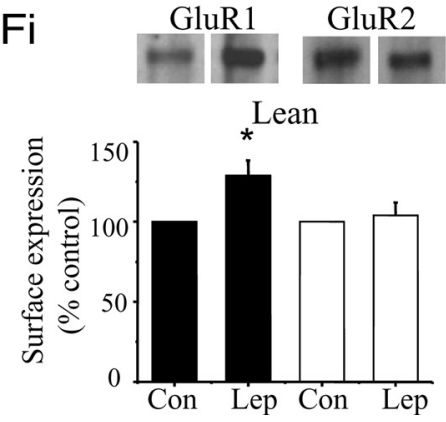

B

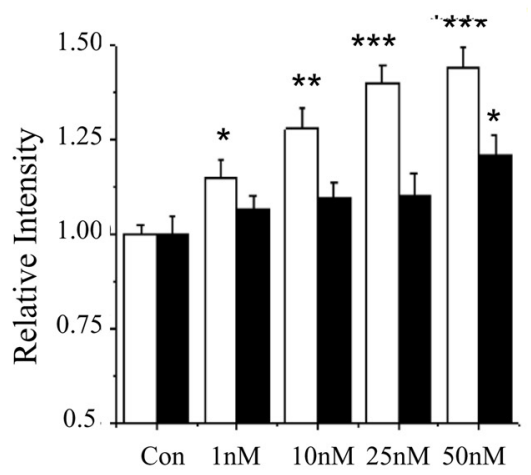

$\mathrm{D}$

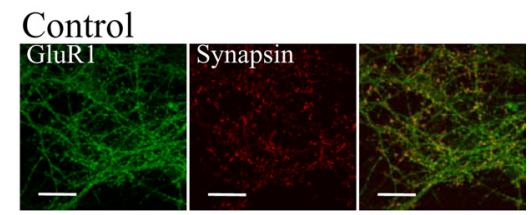

Leptin

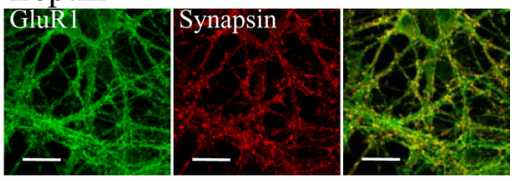

Eii

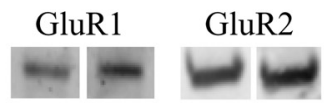

13-16 week

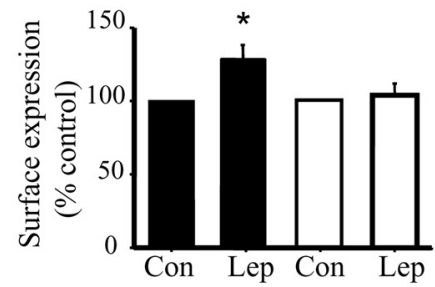

Fii

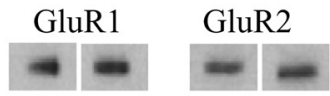

$\mathrm{Fa} / \mathrm{Fa}$

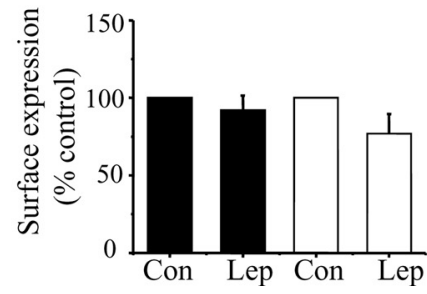

Figure 1. Leptin increases the surface expression of AMPA receptors. $A$, Representative confocal images of surface (green) and total (blue) GluR1 staining in control and leptin-treated hippocampal neurons. Leptin ( $50 \mathrm{~nm} ; 30 \mathrm{~min}$ ) increased GluR1 surface labeling. Scale bars, $10 \mu \mathrm{m} . \boldsymbol{B}$, Pooled data showing the concentration-dependent effects of leptin on GluR1 (open bars) and GluR2 (filled bars) surface expression. C, Pooled data showing relative changes in surface GluR1 labeling in control conditions, after exposure to leptin ( $50 \mathrm{~nm}$ ), NEM (5 $\mathrm{mM})$, brefeldin $\mathrm{A}(5 \mu \mathrm{m})$, and in the presence of either NEM or brefeldin A and leptin. $\boldsymbol{D}$, Representative images of surface GluR1 staining (green) and synapsin-1 staining (red) in control and leptin-treated neurons. Leptin (50 nм; $30 \mathrm{~min}$ ) increased GluR1 surface labeling associated with synapses. $\boldsymbol{E}, \boldsymbol{F}$, Surface expression of AMPA receptors as determined using cell surface biotinylation. Top, Representative Western blots of surface GluR1 and GluR2 in control and leptin-treated slices from 3- to 4-week-old (Ei) and 13- to 16-week-old (Eii) Sprague-Dawley rats and from 13- to 14-week-old Zucker lean (Fi) and fa/fa (Fii) rats. Bottom, Corresponding histograms of GluR1 (filled bars) and GluR2 (open bars) surface expression in control conditions and after treatment with leptin ( $25 \mathrm{~nm} ; 15 \mathrm{~min}$ ). In this and subsequent figures*,**, and ${ }^{* * *}$ represent $p<0.05, p<0.01$, and $p<0.001$, respectively.

creased synapsin- 1 staining to $113.4 \pm 4 \%$ of control $(n=21 ; p<0.05)$. Moreover leptin increased surface GluR1 that colocalized with synapsin-1 staining from $33.7 \pm 2.6 \%$ to $48.9 \pm 3.1 \%(n=21 ; p<$ 0.05 ) (Fig. 1D). These data indicate that leptin promotes the synaptic expression of GluR1.

To determine directly how the immunocytochemical findings from hippocampal cultures relate to excitatory synaptic transmission, we assessed initially at what stage of development the effects of leptin on acute hippocampal slices mirrored those observed effects in culture. Thus, in parallel studies, we examined the effects of leptin on AMPA receptor expression in hippocampal slices using cell surface biotinylation assays. Exposure of adult slices (13-16 weeks old) to leptin (25 nM; 15 min) increased GluR1 (129 $\pm 9.5 \%$ of control; $n=6$; $p<0.05)$ but not GluR2 $(104 \pm 7.9 \%$ of control; $n=6 ; p>0.05)$ surface expression. Application of leptin (25 $\mathrm{nM} ; 15 \mathrm{~min})$ to younger slices $(3-4$ weeks old) had no effect on GluR1 (94 \pm $12 \%$ of control; $n=3 ; p>0.05$ ) or GluR2 $(88 \pm 21 \%$ of control; $n=3 ; p>0.05)$ surface expression (Fig. 1 Ei,Eii). It is well documented that Zucker $\mathrm{fa} / \mathrm{fa}$ rats contain a mutation in the leptin receptor that renders them leptin-insensitive. Thus, to determine whether leptin receptor activation was required, we also examined the effects of leptin on GluR1 and GluR2 expression in hippocampal slices from adult Zucker $f a / f a$ or lean rats using cell surface biotinylation assays. In agreement with results from adult (13- to 16-week-old) rats, exposure of slices from Zucker lean rats to leptin ( $25 \mathrm{nM}, 15 \mathrm{~min})$ increased GluR1 (128 $\pm 13 \%, n=9 / 3 ; p<0.05)$ but not GluR2 (94 $\pm 14 \%, n=9 / 3 ; p>0.05)$ surface expression. In contrast, exposure of slices from $f a / f a$ rats to leptin had no effect on either GluR1 (91 $\pm 15 \%, n=$ 9/3; $p>0.05)$ or GluR2 $(107 \pm 15 \%, n=$ 9/3; $p>0.05$ ) surface expression (Fig. 1Fi,Fii). Thus, these data indicate that leptin receptor activation is required for the increase in GluR1 surface expression.

To determine the consequences for hippocampal synaptic function, the effects of leptin on EPSCs were examined in adult (13- to 16-week-old) slices. Application of $25 \mathrm{~nm}$ leptin (15 min) produced a robust enhancement of EPSCs to $197 \pm$ $10 \%(n=6 ; p<0.001)$ of baseline (Fig. $2 A, B)$, which was maintained for the duration of recordings (up to $90 \mathrm{~min}$ ). Changes in paired pulse ratio (PPR) or the CV classically reflect alterations in release probability $\left(P_{\mathrm{r}}\right)$. To identify the locus of 
this effect of leptin we analyzed PPR and $\mathrm{CV}$ in the above experiments, by delivering two pulses at an interval of $50 \mathrm{~ms}$. The leptin increase in EPSC amplitude was not accompanied by any significant change in PPR $(n=6 ; p>0.05)$ (Fig. $2 C)$ or $\mathrm{CV}$ $(n=6 ; p>0.05)$ (Fig. $2 D)$, indicating the likely involvement of a postsynaptic expression mechanism rather than altered $P_{r}$. The effects of leptin were also examined in slices from leptin-insensitive rats (Zucker $f a / f a$ ) and in lean animals (12-16 weeks old). Leptin (25 nM) increased EPSC amplitude to $190 \pm 14 \%$ of control $(n=6 ; p<0.05)$ in Zucker lean animals, but it had no significant effect on EPSCs (102 $\pm 6 \%$ of control) in $f a / f a$ animals $(n=6 ; p>0.05)$ (Fig. 2E), indicating that leptin receptor activation was required for the effects of leptin.

GluR2-lacking AMPA receptors are $\mathrm{Ca}^{2+}$-permeable and display pronounced inward rectification (Koh et al., 1995) that is due to high affinity voltage-dependent block of the channel by endogenous polyamines at positive membrane potentials. To determine whether leptin alters the GluR2 content of synaptic AMPA receptors, the rectification properties of EPSCs were monitored during whole-cell recordings with spermine-containing pipettes, as described previously (Moult et al., 2009). Application of leptin (25 nM; 15 $\mathrm{min}$ ) increased EPSC amplitude to $186 \pm$ $10 \%$ of control $(n=6)$, and this was accompanied by an increase in rectification index (RI) from $1.3 \pm 0.2$ to $2.2 \pm 0.3$ $(n=6 ; p<0.05)$ (Fig. $2 F-H)$. In interleaved control experiments, no significant change in RI was detected using sperminelacking pipettes $(n=6 ; p>0.05)$ (Fig. $2 G, H)$. Application of philanthotoxin (1 $\mu \mathrm{M})$, a selective inhibitor of GluR2lacking AMPA receptors, blocked the inserted receptors resulting in a decrease in synaptic transmission (from $212 \pm 12 \%$ of control) to $110 \pm 12 \%(n=6 ; p<0.05)$ (Fig. 2I). These data are consistent with leptin increasing the density of GluR2lacking AMPA receptors at hippocampal synapses.

Our data indicate that leptin increases GluR1 surface expression by promoting GluR1 exocytosis. Thus, we examined whether the increase in synaptic strength induced by leptin involved increased GluR1 exocytosis, by inclusion of inhibitors of exocytosis in the pipette (Fig. $2 J$ ). Both NEM ( $5 \mathrm{mM})$ and brefeldin A $(5 \mu \mathrm{M})$ attenuated the potentiation caused by leptin $(105 \pm 8 \% ; n=6$; $p>0.05$ and $112 \pm 8 \% ; n=6 ; p>0.05$, respectively). The effects of bafilomycin $(1 \mu \mathrm{M})$, an inhibitor of endocytosis, were also examined. In neurons dialyzed with bafilomycin, leptin resulted in a control (filled circles).
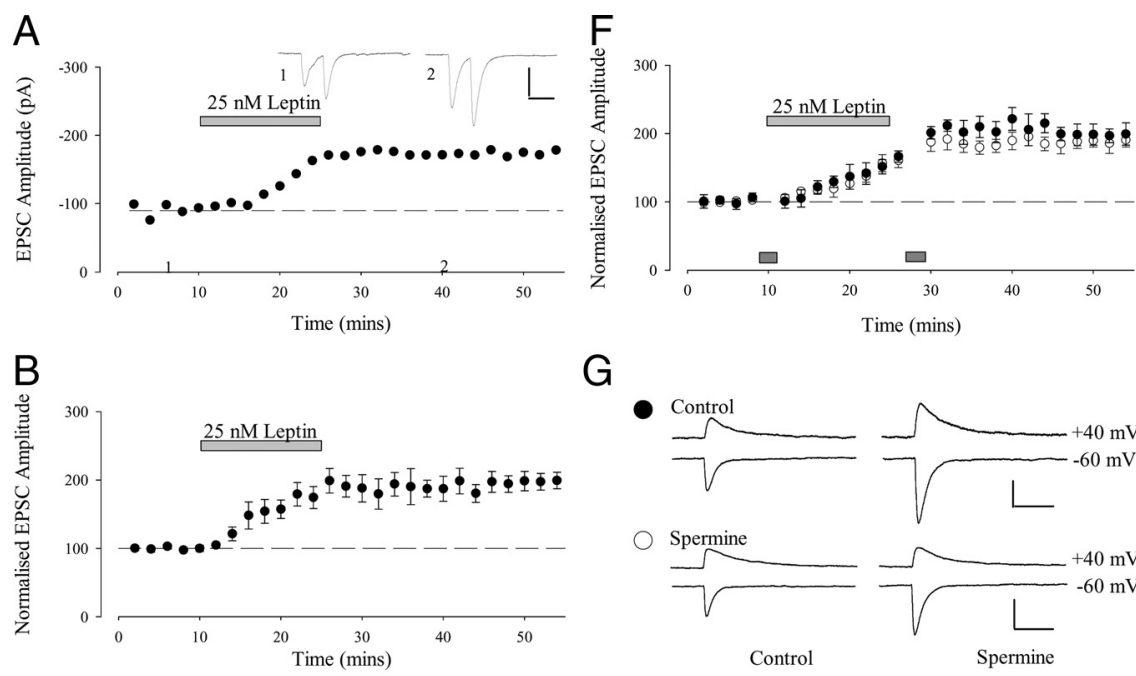

G
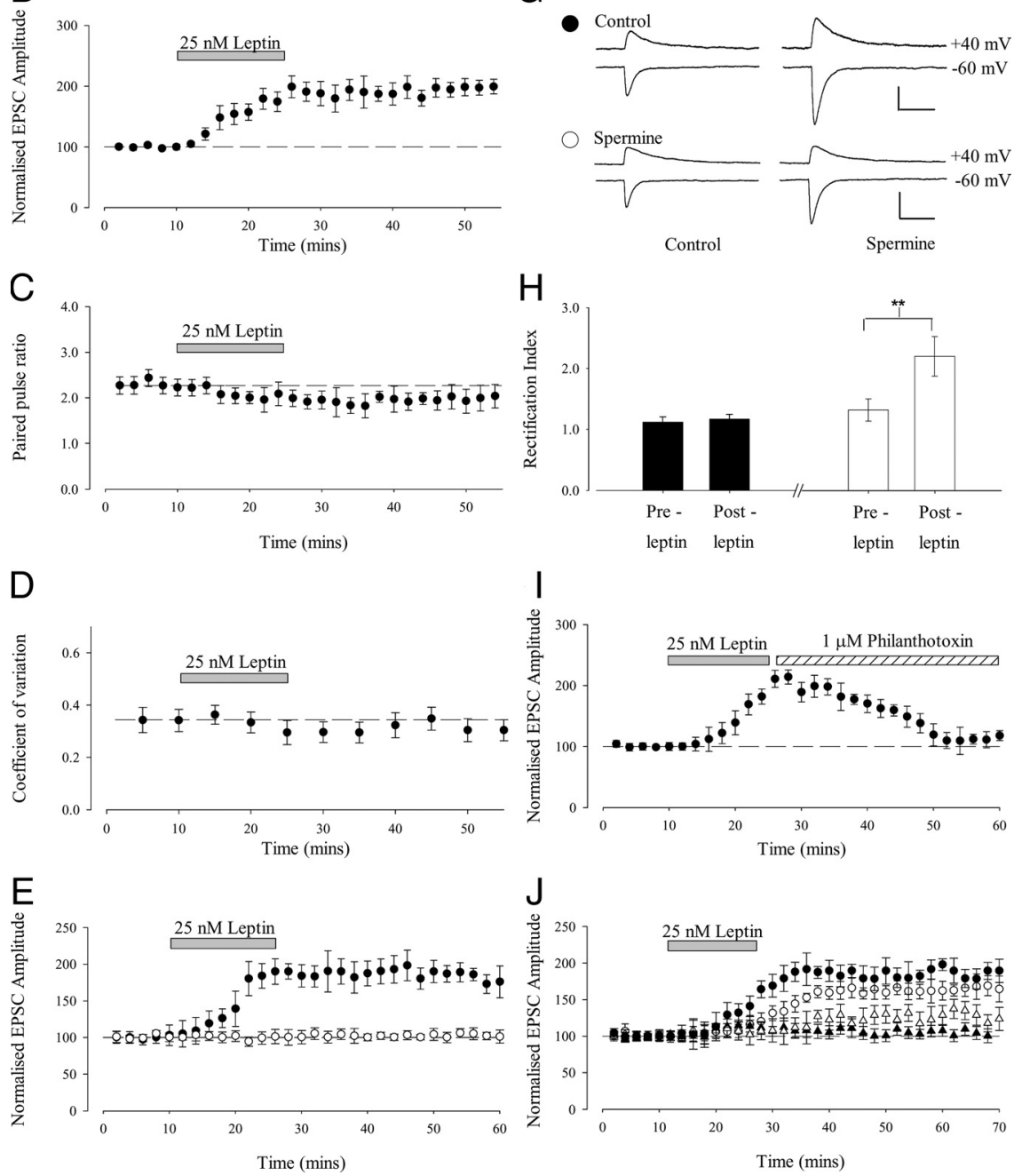

Figure 2. Leptin increases the synaptic density of GluR2-lacking AMPA receptors. $A$, Representative experiment showing that leptin potentiates EPSCsin hippocampal slices. In this and subsequent figures, each point is the average offour successive responses. Top, Example traces from the experiment are shown for the time points indicated. Calibration: $50 \mathrm{pA}, 50 \mathrm{~ms}$. B, Pooled and normalized data from all experiments. In this and subsequent figures, data are mean EPSC amplitude \pm SEM. C, D, PPR ( $C$ and CV (D) calculated throughout the same set of experiments shows no significant change. $\boldsymbol{E}$, The leptin-induced increase in synaptic strength requires leptin receptor activation. Pooled and normalized data demonstrating that application of leptin (25 nM) induces potentiation of EPSCs in hippocampal slices from Zucker lean rats (filled circles), but not in slices from Zucker fa/fa rats (open circles). $\boldsymbol{F}$, Summary data of recordings made with sperminecontaining pipettes. Interleaved control experiments using intracellular solution lacking spermine are also shown. Cells were depolarized to $+40 \mathrm{mV}$ for times indicated (gray bars). G, Example EPSCsfrom a representative experiment in $F$. EPSCs are shown for control and spermine experiments. Calibration: $50 \mathrm{pA}, 50 \mathrm{~ms}$. $\boldsymbol{H}$, Leptin-induced increases in EPSC amplitude are associated with increased rectification of AMPA receptors. Pooled RI calculations from the same set of experiments shown in $\boldsymbol{F}$. I, Leptin increases in EPSC amplitude is reversed by philanthotoxin $(1 \mu \mathrm{M}) . J$, Leptin increases synaptic transmission by promoting exocytosis of AMPA receptors. The leptin-induced increases in EPSC amplitude are attenuated by blockers of exocytosis. Histogram of the pooled data showing the relative effects of leptin on EPSC amplitude in the presence of NEM ( $5 \mathrm{~mm}$; filled triangles), brefeldin A ( $5 \mu \mathrm{m}$; open triangles), or bafilomycin ( $1 \mu \mathrm{m}$; open circles) versus 
A

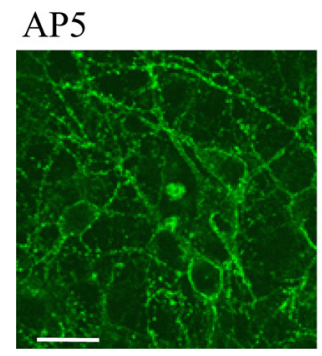

AP5 + Leptin

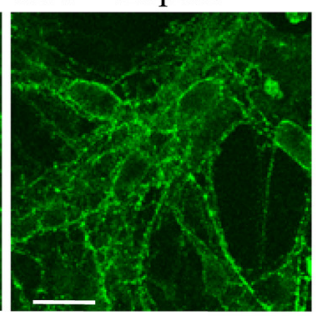

B

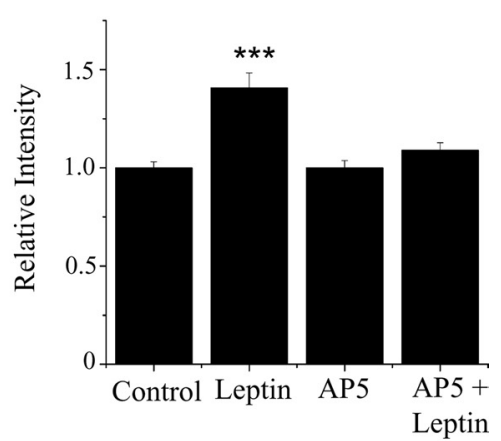

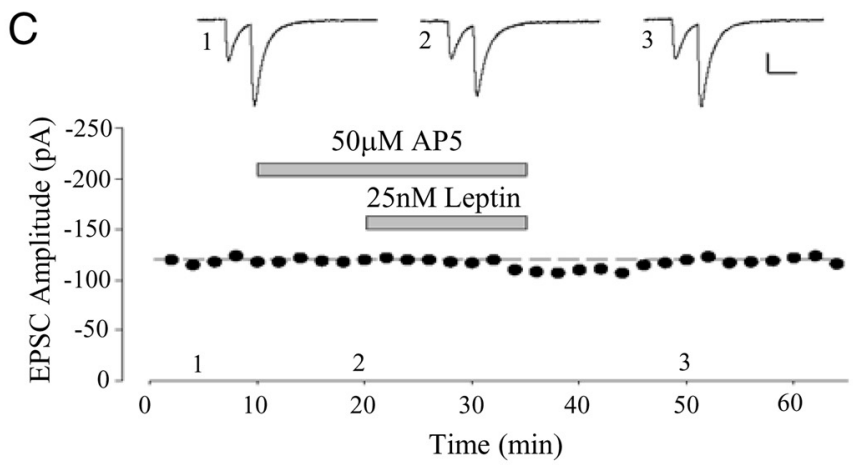

D

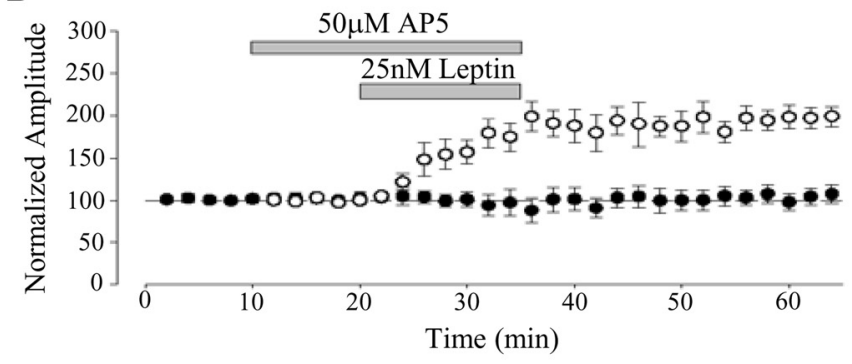

$\mathrm{E}$

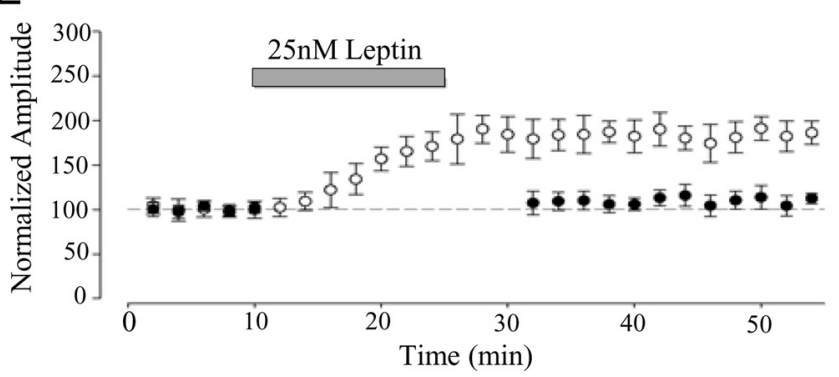

Figure 3. Leptin increases surface GluR1 expression via an NMDA receptor-dependent process. $\boldsymbol{A}$, Representative confocal images of surface GluR1 labeling in cultures treated with AP5 (50 $\mu \mathrm{m}$; left) or in AP5 and leptin ( $50 \mathrm{~nm}$; right). The leptin increase in surface GluR1 staining was blocked by AP5. B, Pooled data showing relative changes in surface GluR1 staining in control conditions, after addition of leptin or D-AP5, and in the presence of D-AP5 and leptin. C, Representative experiment demonstrating that D-AP5 prevented the increase in EPSC amplitude by leptin in hippocampal slices. Top, Example traces are shown for the time points indicated. Calibration: 50 pA, $50 \mathrm{~ms}$. D, Pooled data of the experiment illustrated in C comparing the effects of leptin in the absence (open circles) and presence (filled circles) of AP5. $\boldsymbol{E}$, Pooled data illustrating the effects of leptin in a two-pathway experiment. In the test pathway (filled circles) synaptic stimulation was stopped during application of leptin. In contrast stimulation was maintained in the control path (open circles). Leptin failed to significantly alter synaptic transmission in the absence of synaptic transmission.

Leptin increases surface GluR1 expression via an NMDA receptor-dependent process

NMDA receptor activation is required for LTP induction (Collingridge et al., 1983) and the membrane insertion of AMPA receptors during LTP (Man et al., 2003). To verify whether the effects of leptin involved NMDA receptors, the effects of the competitive NMDA receptor antagonist D-AP5 were assessed. D-AP5 ( $50 \mu \mathrm{M} ; 30 \mathrm{~min}$ ) had no effect on surface GluR1 staining $(96.1 \pm 3.5 \%$ of control; $n=37$; $p<0.05)$ per se. However, the leptin increase in GluR1 surface staining (141 $\pm 7.7 \% ; n=37)$ was reduced to $109 \pm 3.8 \%$ of control $(n=37$; $p>0.05$ ) in D-AP5 (Fig. $3 A, B$ ). The ability of leptin to increase synaptic strength was attenuated in the presence of D-AP5 such that leptin increased synaptic transmission to only $103 \pm 9 \%$ of baseline $(n=$ $6 ; p>0.05$ ), an effect significantly different to interleaved control experiments $(n=6 ; p<0.05)$ (Fig. 3C,D). We also evaluated whether leptin altered the magnitude of NMDA receptor-mediated EPSCs as leptin enhances pharmacologically isolated NMDA EPSCs in juvenile hippocampus (Shanley et al., 2001). Similarly, in adult hippocampus leptin (25 nM) increased the amplitude of NMDA EPSCs ( $175 \pm 9 \%$ of control; $n=5 ; p<0.05)$, an effect that readily reversed on leptin washout. The leptin-induced increase in EPSCs was associated with a significant increase in the NMDA receptor-mediated component of the EPSC (amplitude of EPSC at $+40 \mathrm{mV}$, at $60 \mathrm{~ms}$ latency) to $131 \pm 11 \%$ of control $(n=6$; $p<0.05)$, but no change in the AMPA component (initial slope of EPSC at $+40 \mathrm{mV}$ ) was detected $(102 \pm 5 \% ; n=6 ; p>0.05)$. This small increase in NMDA receptor current is likely to be sufficient for the NMDA receptor-dependent enhancement of synaptic strength by leptin. However, to show conclusively that synaptic activation of NMDA receptors was required, a twopathway experiment was performed such that during leptin application stimulation was stopped in the test pathway but maintained in the control pathway. Under these conditions, leptin failed to significantly increase synaptic transmission in the test pathway $(109 \pm 10 \% ; n=5 ; p>$ $0.05)$ whereas leptin markedly increased EPSCs in the control path $(188 \pm 14 \%$; $n=5 ; p<0.001$ ) (Fig. 3E). These data indicate that leptin increases the density of functional AMPA receptors at hippocampal synapses via a process requiring the synaptic activation of NMDA receptors.

It is well established that NMDA receptors are highly permeable to $\mathrm{Ca}^{2+}$ and that $\mathrm{Ca}^{2+}$ influx via NMDA receptors is pivotal for various forms of activity-dependent changes in synaptic efficacy (Nicoll and Malenka, 1999). Thus, as the leptin-driven increase in synaptic strength requires the synaptic activation of NMDA receptors, we examined whether $\mathrm{Ca}^{2+}$ influx via NMDA receptors was also 


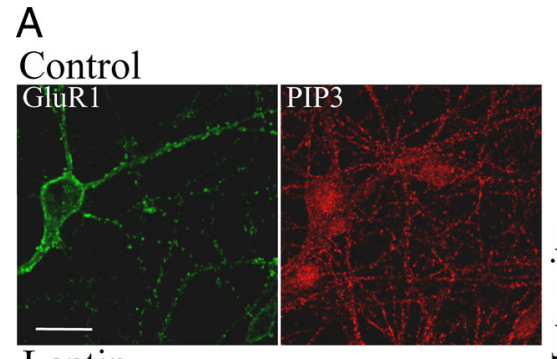

B
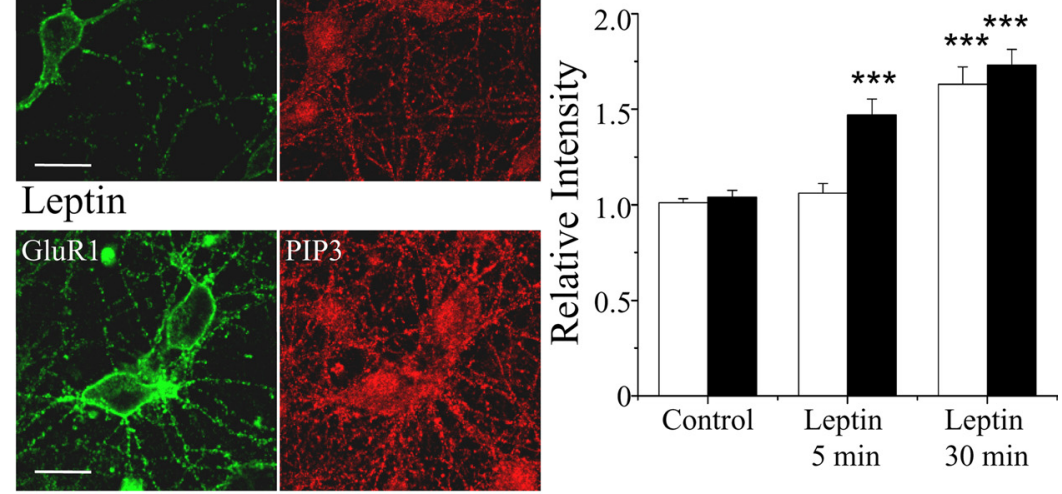

C

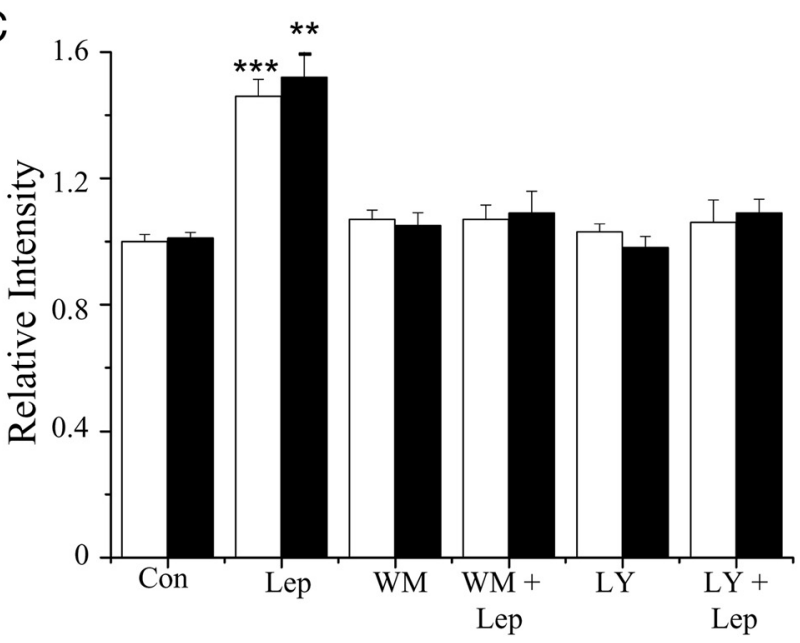

$\mathrm{D}$

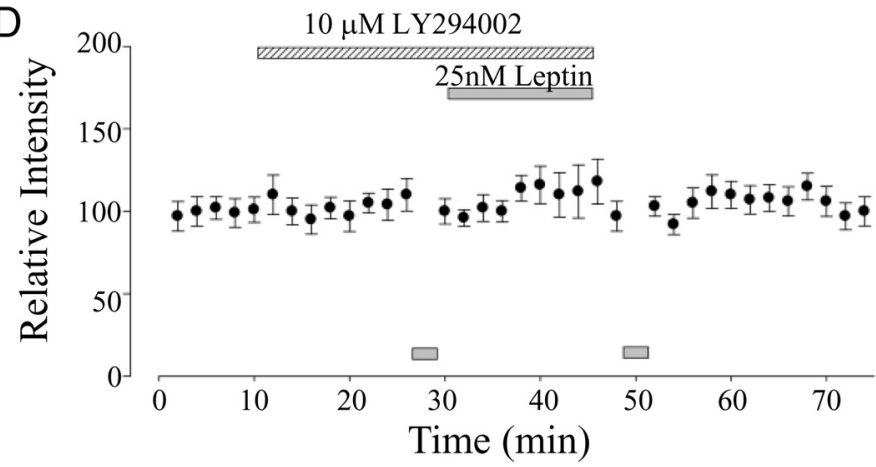

$\mathrm{E}$

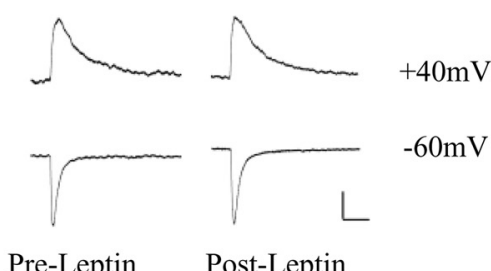

Figure 4. Leptin increases surface GluR1 via a PI 3-kinase-dependent increase in Ptdlns $(3,4,5) \mathrm{P}_{3}$ levels. $\boldsymbol{A}$, Representative confocal images of surface GluR1 (green) and Ptdlns $(3,4,5) P_{3}$ (red) staining in control and leptin-treated neurons. Leptin $(50 \mathrm{~nm} ; 30$ $\mathrm{min}$ ) increased GluR1 surface labeling and Ptdlns $(3,4,5) \mathrm{P}_{3}$ levels. $\boldsymbol{B}$, Pooled data showing relative changes in surface GluR1 (open bars) and Ptdlns $(3,4,5) P_{3}$ (filled bars) in control conditions and after leptin exposure for 5 min and $30 \mathrm{~min}$. C, Pooled data showing relative changes in surface GluR1 (open bars) and Ptdlns $(3,4,5) \mathrm{P}_{3}$ (filled bars) labeling in control conditions and after leptin ( $50 \mathrm{~nm}$; $30 \mathrm{~min}$ ), wortmannin ( $50 \mathrm{~nm} ; 30 \mathrm{~min}$ ), or LY294002 (10 $\mu \mathrm{m} ; 30 \mathrm{~min}$ ) alone, or in the presence of either wortmannin or LY294002 and leptin. $\boldsymbol{D}$, Pooled and normalized data for all experiments showing that LY294002 (10 $\mu \mathrm{M})$ prevents potentiation of EPSCs by required for this effect. In this series of experiments, whole-cell recordings were made using recording pipettes containing the $\mathrm{Ca}^{2+}$ chelator, BAPTA (10 mM). After at least 30 min dialysis with the BAPTAcontaining solution, application of leptin failed to significantly alter synaptic transmission $(107 \pm 14 \%$ of baseline; $n=4$; $p>0.05)$, indicating that an increase in intracellular $\mathrm{Ca}^{2+}$ is required for the leptin-dependent facilitation of synaptic transmission.

Leptin-induced increase in surface GluR1 is correlated with an increase in PtdIns $(3,4,5) \mathrm{P}_{3}$ levels

PI 3-kinase is a key element of neuronal leptin receptor-driven signaling (Harvey, 2007), and it is required for AMPA receptor insertion during LTP (Man et al., 2003). As PI 3-kinase phosphorylates PtdIns $(4,5) \mathrm{P}_{2}$ into $\operatorname{PtdIns}(3,4,5) \mathrm{P}_{3}$, the increase in surface GluR1 may be due to enhanced PtdIns $(3,4,5) \mathrm{P}_{3}$ levels. To address this, dual labeling was used to simultaneously compare surface GluR1 staining and the intracellular levels of PtdIns $(3,4,5) \mathrm{P}_{3}$ in cultures. Leptin (25 $\mathrm{nM} ; 30 \mathrm{~min}$ ) increased surface GluR1 staining (163 $\pm 9.1 \%$ of control; $n=30$; $p<0.001)$ with a parallel increase in PtdIns $(3,4,5) \mathrm{P}_{3}$ staining $(173 \pm 8.3 \%$ of control; $n=30 ; p<0.001$ ) (Fig. $4 A, B$ ). Shorter-duration applications of leptin (5 min) increased PtdIns $(3,4,5) \mathrm{P}_{3}$ staining $(147 \pm 8.3 \%$ of control; $n=25 ; p<$ $0.001)$ with no significant alteration in surface GluR1 staining (106 $\pm 5.1 \%$ of control; $n=25 ; p>0.05)$, suggesting that leptin increases $\operatorname{PtdIns}(3,4,5) \mathrm{P}_{3}$ levels which in turn drives the alterations in GluR1 trafficking.

We further characterized the connection between surface GluR1 expression and PI 3-kinase/PtdIns $(3,4,5) \mathrm{P}_{3}$ using the well characterized PI 3-kinase inhibitors wortmannin and LY294002, because processes dependent on class I PI 3-kinasegenerated PtdIns $(3,4,5) \mathrm{P}_{3}$ are sensitive to these inhibitors. Blockade of PI 3-kinase activity with wortmannin (10 nM; $30 \mathrm{~min})$ or LY294002 (10 $\mu \mathrm{M} ; 30 \mathrm{~min})$ had no effect on surface GluR1 or PtdIns $(3,4,5) \mathrm{P}_{3}$ levels (Fig. 4C). However, wortmannin reduced the leptin driven increase in GluR1 surface staining to $107 \pm 4.5 \%$

leptin ( $25 \mathrm{~nm}$ ) in slices. Spermine $(0.1 \mathrm{~mm})$ was included in the recording pipette, and cells were depolarized to $+40 \mathrm{mV}$ where indicated (gray bars). $\boldsymbol{E}$, Representative examples of EPSCs obtained at time points indicated in $\boldsymbol{D}$. 
A
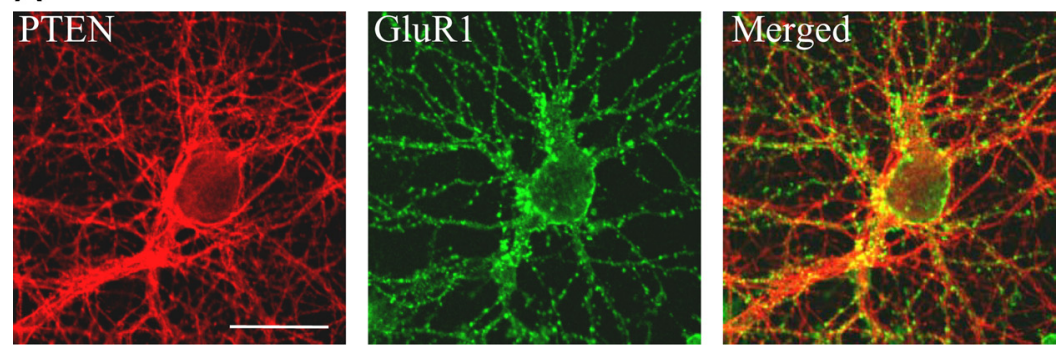

B
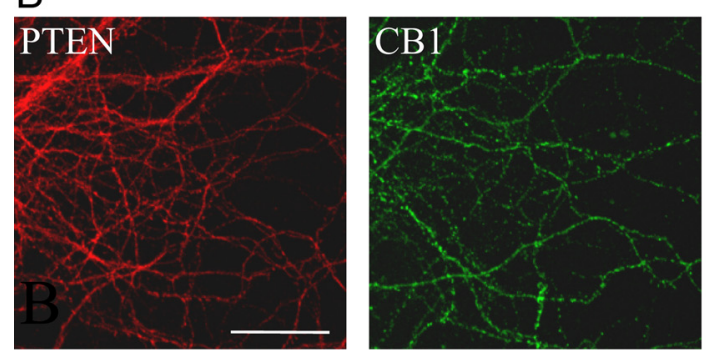

C
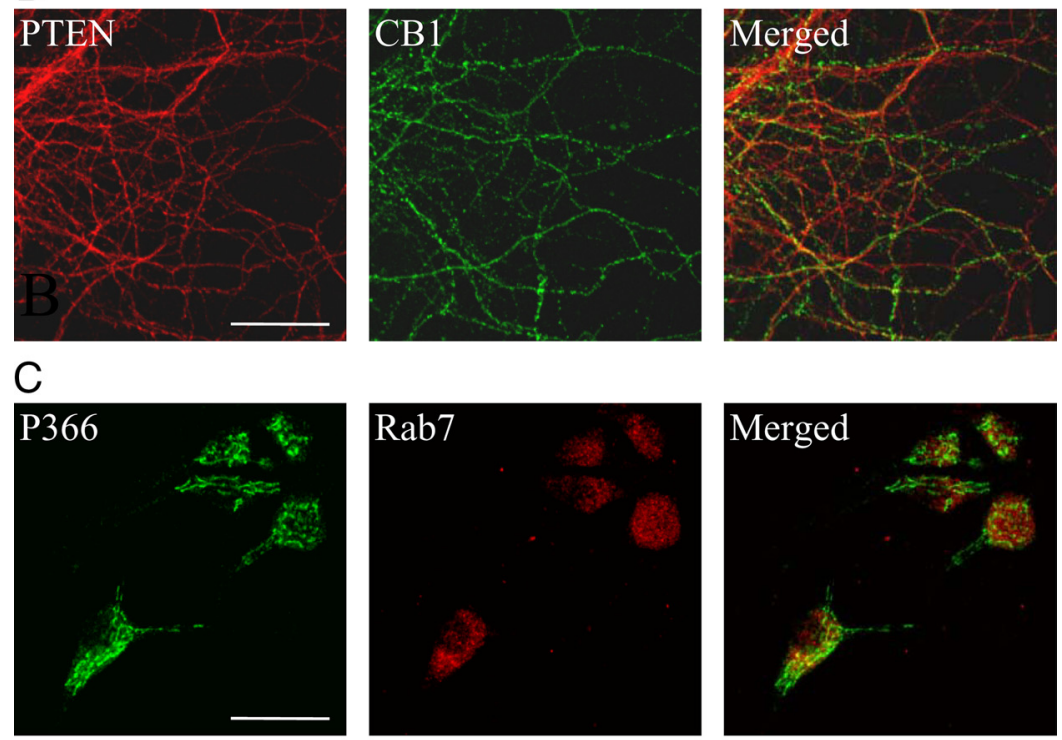

D
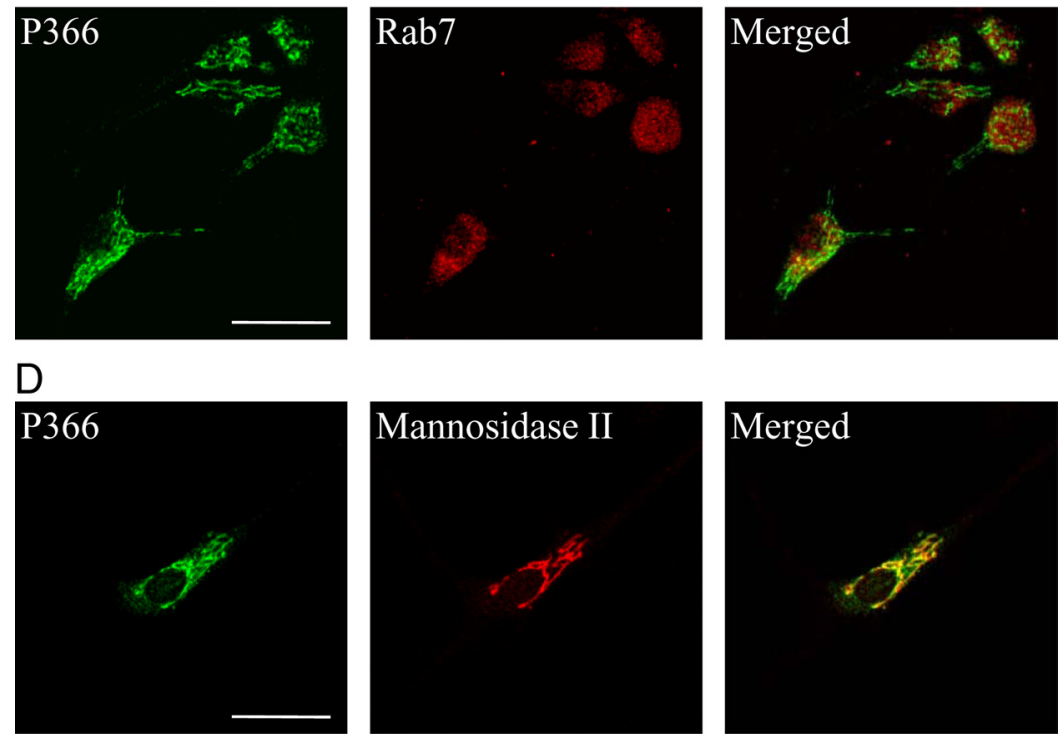

Figure 5. Cellular distribution of PTEN in hippocampal neurons. $\boldsymbol{A}$, Representative confocal images of PTEN and surface GluR1 labeling in hippocampal neurons (9DIC). The merged image shows that PTEN is associated with somato-dendritic regions. $\boldsymbol{B}$, Confocal images of PTEN, surface $(B 1$ receptor labeling, and the merged image. $\boldsymbol{C}, \boldsymbol{D}$, Representative confocal images of P366-PTEN $(\boldsymbol{C}, \boldsymbol{D})$ and either Rab7 ( $\boldsymbol{C}$ ) or mannosidase II ( $\boldsymbol{D})$ labeling. The corresponding merged images are also displayed in $\boldsymbol{C}$ and D. Scale bars, $10 \mu \mathrm{m}$.

$(n=33 ; p>0.05)$, compared with $146 \pm 5.3 \%(n=33 ; p<$ $0.001)$ in control. The leptin-induced increase in $\operatorname{PtdIns}(3,4,5) \mathrm{P}_{3}$ levels was also reduced from $152 \pm 8.2 \%$ in control $(n=30 ; p<$ $0.01)$ to $109 \pm 6.9 \%(n=30 ; p<0.01)$ in wortmannin. Exposure to LY294002 also attenuated leptin's effects such that the increase in surface GluR1 staining by leptin was reduced from $138 \pm 5.2 \%$ to $106 \pm 4.4 \%(n=29 ; p>0.05)$, whereas the leptin-induced increase in PtdIns $(3,4,5) \mathrm{P}_{3}$ staining was reduced from $147 \pm$ $5.6 \%(n=35 ; p<0.01)$ to $109 \pm 7.1 \%(n=35 ; p<0.05)$ in the presence of LY294002. In parallel studies the ability of leptin to enhance excitatory synaptic strength was prevented by prior exposure to either LY294002 $(n=6)$ (Fig. $4 D)$ or wortmannin $(n=$ 6). LY294002 also prevented any significant leptin-driven changes in AMPA receptor rectification $(1.38 \pm 0.14$ to $1.43 \pm 0.20 ; n=6$; $p>0.05)$. These data indicate that a PI 3-kinase-dependent process underlies the leptin-driven increase in GluR1 surface expression and PtdIns $(3,4,5) \mathrm{P}_{3}$ levels.

\section{PTEN and phosphorylated PTEN are localized to distinct subcellular} compartments in hippocampal neurons Although our data suggest that leptin increases surface GluR1 expression, via a PI 3-kinase-dependent increase in PtdIns $(3,4,5) \mathrm{P}_{3}$, the possibility that leptin uses an alternative mechanism to raise intracellular PtdIns $(3,4,5) \mathrm{P}_{3}$ levels cannot be excluded. It is known that the PtdIns $(3,4,5) \mathrm{P}_{3}$ levels are also regulated by PTEN. Although PTEN plays an important role in the CNS, there is limited information about its cellular distribution in neurons. Thus, initially the functional localization of PTEN was assessed in cultured hippocampal neurons immunocytochemically. PTEN labeling was present on principle neurons in hippocampal cultures. Comparison of PTEN immunoreactivity with surface cannabinoid CB1 receptor labeling, an axonal marker (Coutts et al., 2001), and surface GluR1 staining which is restricted to somato-dendritic regions, demonstrated high levels of PTEN expression within these neuronal compartments (Fig. 5A). Dual labeling with an antibody against synapsin-1 also revealed clusters of PTEN labeling associated with synapses (data not shown).

As the phosphorylation status of PTEN is important for its function, the distribution of PTEN when phosphorylated on one key site, threonine 366 (P366-PTEN), was compared. In contrast to PTEN distribution, the phosphorylated form of PTEN exhibited a very distinct cellular distribution such that labeling was restricted to specific submembrane cytoplasmic regions within somata and dendrites. Dual labeling studies demonstrated that when phosphorylated, PTEN localized to the Golgi apparatus as P366PTEN labeling directly correlated with the Golgi marker, mannosidase II, but to a much lesser extent with the endosomal markers Rab7 (20 $\pm 5 \%$ colocalization; $n=6$ ) (Fig. $5 B$ ) and Rab5 (17 $\pm 4 \%$ colocalization; $n=4)$. Thus, these data suggest that phosphorylation of PTEN significantly alters the subcellular localization of PTEN such that it is limited to the Golgi apparatus.

Leptin promotes PTEN inactivation in hippocampal neurons One way of modulating PTEN function is by phosphorylation, which results in inactivation of this phosphatase (Downes et al., 2007). Recent studies have implicated increased phosphorylation and inhibition of PTEN in leptin receptor coupling to $\mathrm{K}_{\mathrm{ATP}}$ channels (Ning et al., 2006; Plum et al., 2006). Thus, we examined the effects of leptin on P366-PTEN labeling in hippocampal neurons. Leptin produced an increase in P366-PTEN labeling to 
A

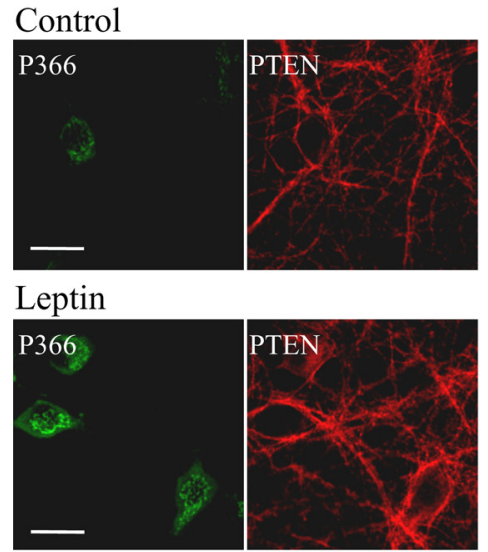

B

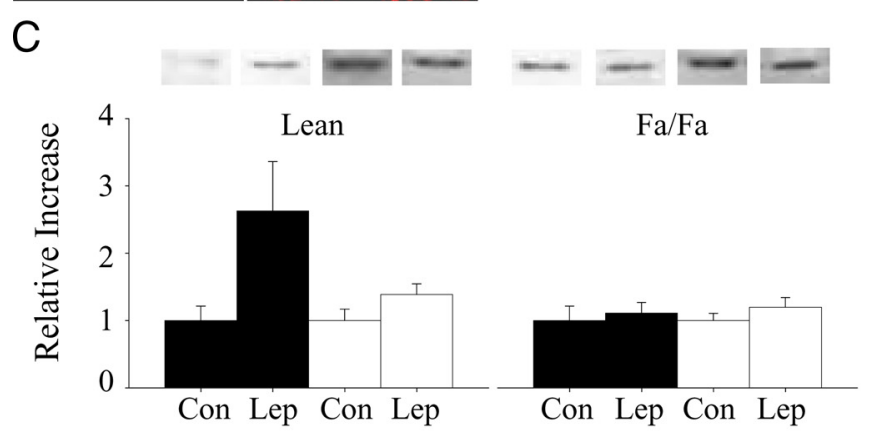

D

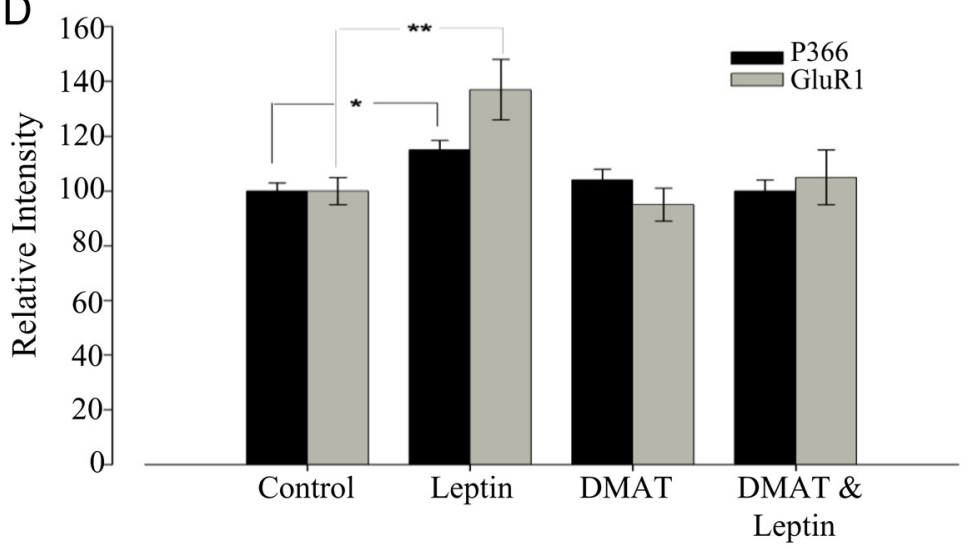

E

$$
\text { Control }
$$

$1 \& 2$
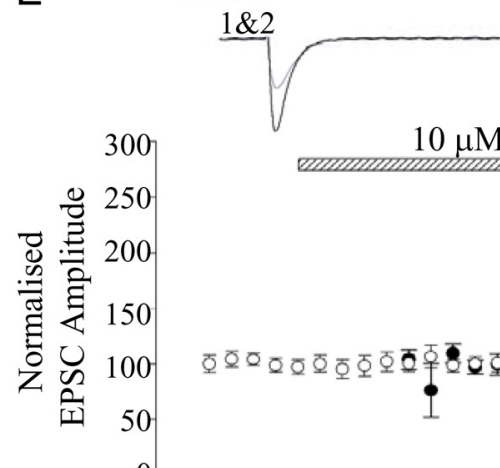

$10 \mu \mathrm{M}$

DMAT

$1 \& 2$
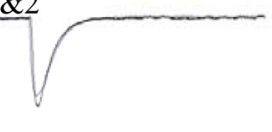
A

G129E

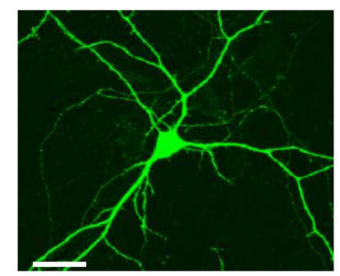

$\mathrm{Bi}$

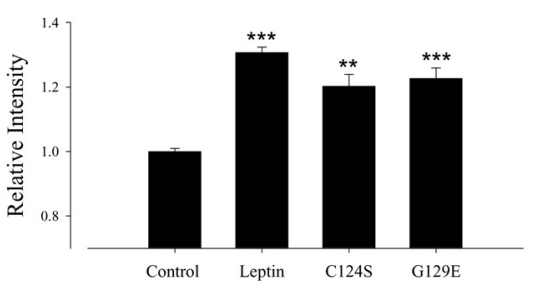

$\mathrm{Ci}$
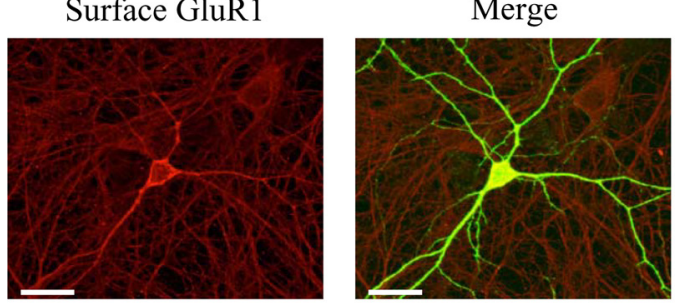

Bii

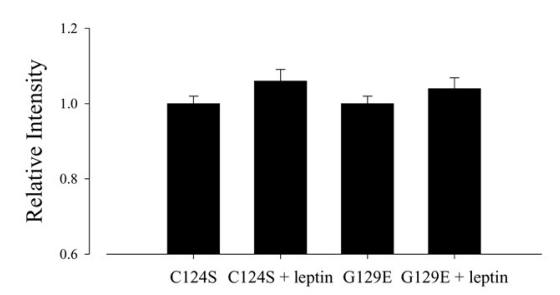

Cii

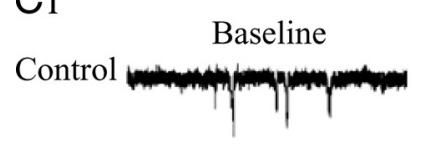

G129E

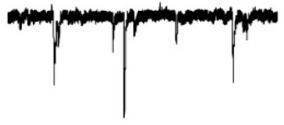

C124S

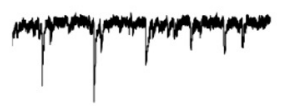
L

Leptin
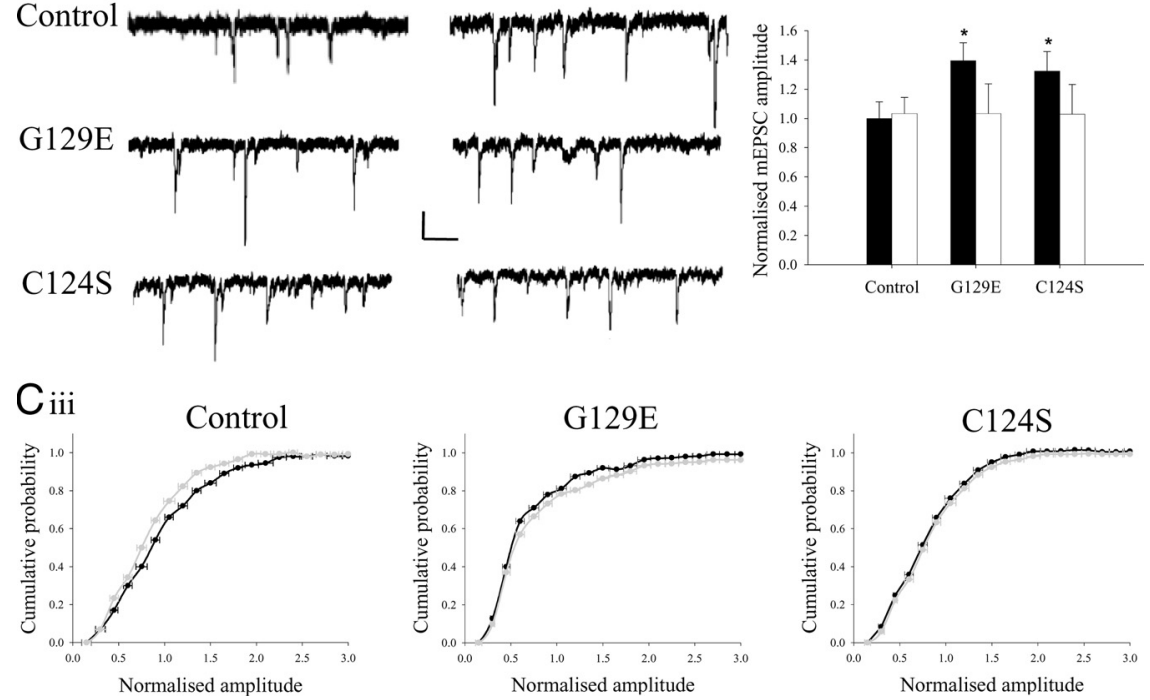

Figure 7. Inhibition of PTEN increases surface expression of GluR1 and occludes the effects of leptin. $\boldsymbol{A}$, Representative confocal images of surface GluR1 labeling in a cultured hippocampal neuron transfected with the PTEN G129E construct alongside untransfected control neurons. Bi, Pooled data showing relative changes in surface GluR1 labeling in leptin-treated neurons or those transfected with C124S or G129E. Bii, Pooled data showing relative changes in surface GluR1 labeling in response to leptin in neurons transfected with either C124S or G129E. Ci, Representative mEPSCs recorded from neurons transfected with either C124S, G129E, or neighboring untransfected cells either immediately before or $15 \mathrm{~min}$ after leptin application. Calibration; 20 pA, 100 ms. Cii, Pooled data showing normalized mEPSC amplitude in neighboring control neurons or those transfected with either C 1245 or G129E (filled bars). Open bars show pooled data from the same cells 15 min after philanthotoxin application. Ciii, Pooled cumulative probability plots showing a change in amplitude elicited by leptin (gray plot) in control neurons, but not in those transfected with either $\mathrm{G} 129 \mathrm{E}$ or $\mathrm{C} 124 \mathrm{~S}$ versus baseline (black plot).

of PTEN and subsequent alterations in glutamate receptor trafficking and synaptic strength by leptin.

Inhibition of PTEN mimics and occludes the effects of leptin Our data suggest that leptin promotes increases in $\operatorname{PtdIns}(3,4,5) \mathrm{P}_{3}$ and surface GluR1 levels via PTEN inhibition. Consequently, to explore the role of PTEN further, we examined the effects of two dominant-negative PTEN mutants on surface GluR1 staining. Cultured hippocampal neurons were transfected with either one of the PTEN mutants (PTEN C124S or PTEN G129E) or the empty vector (EGFP-C2). Cells transfected with either PTEN C124S or PTEN G129E showed a significant increase in surface GluR1 labeling relative to control cells transfected with the empty vector (120.2 $\pm 4 \%$, PTEN. $p<0.01$ and $122.7 \pm 3 \%, p<0.001$ relative to control respectively; $n=27$ for each) (Fig. $7 A, B)$. Leptin failed to increase surface GluR1 staining in cells transfected with PTEN C124S or PTEN G129E (106.1 $\pm 4 \%$, $p>0.05$ and $104.3 \pm 3 \%, p>0.05$ relative to control respectively; $n=27$ for each) (Fig. 7 Bii). Conversely, leptin increased surface GluR1 expression in neighboring nontransfected cells $(130.7 \pm 2 \%, p<0.001$ relative to control; $n=81)$. These data support the idea that PTEN inhibition increases GluR1 surface expression and that leptin increases surface GluR1 via inhibition of PTEN.

We also examined the impact of PTEN inhibition on the properties of mEPSCs in primary hippocampal neurons. Cells were transfected with either of two dominantnegative PTEN constructs, G129E or C124S, and the amplitude and frequency of mEPSCs were compared with neighboring nontransfected control cells. Application of leptin ( $25 \mathrm{nM} ; 15 \mathrm{~min}$ ) resulted in a persistent increase in the amplitude of mEPSCs (amplitude, $141 \pm 10 \%$ of baseline $20 \mathrm{~min}$ after leptin washout, $n=6, p<0.01$ ) (Fig. $7 C)$ with no significant change in mEPSC frequency. This effect of leptin was completely reversed (to $106 \pm 21 \%$ of baseline; $n=3$ ) by addition of the selective antagonist for GluR2-lacking AMPA receptors, philanthotoxin. In contrast, application of leptin to cells transfected with either dominant-negative PTEN construct, G129E or C124S failed to alter mEPSC amplitude $(108 \pm 12 \%$ and $104 \pm 8 \%$ of baseline $20 \mathrm{~min}$ after leptin, respectively; $n=4 ; p>0.05$ for each) (Fig. 7Ci). Furthermore, cells transfected with either G129E or C124S showed significantly higher mean basal mEPSC amplitudes $(139 \pm 12 \%$ and $132 \pm 13 \%$ of control) (Fig. 7Cii,Ciii) with no significant change in mEPSC frequency. In addition, application of philanthotoxin reduced the mean amplitude of mEPSCs recorded from cells transfected with either G129E or C124S to that similar to neighboring control cells (amplitude, $103 \pm 20 \%$ and $103 \pm 20 \%$ of control; $n=4$ for each) while having no effect on basal transmission of neighboring control cells (Fig. 7Cii). Thus, these data indicate that PTEN inhibition selectively increases functional expression of GluR1 at hippocampal synapses and that the ability of leptin to deliver GluR1 subunits to synapses is blocked following inhibition of

As low concentrations of the phosphatase inhibitor bisperoxovanadium (bpV) has been shown to specifically inhibit PTEN (Schmid et al., 2004), the effects of pharmacological inhibition of PTEN with bpV were also assessed. To determine the functional effects of PTEN inhibition, the effects of bpV on evoked EPSCs were examined. Application of $100 \mathrm{~nm}$ bpV produced a robust potentiation of EPSCs to $128 \pm 8 \%$ of baseline $(n=6 ; p<0.001)$ 
(Fig. $8 A, B$ ), which was not accompanied by any significant change in $\operatorname{PPR}(n=6$; $p>0.05)$ (Fig. $8 C)$ or $\mathrm{CV}(n=6 ; p>$ 0.05 ) (Fig. $8 D$ ), indicating the involvement of a postsynaptic change. To determine whether bpV alters the GluR2 content of synaptic AMPA receptors, the RI of evoked EPSCs were monitored. Application of bpV (100 nM) increased EPSC amplitude to $143 \pm 12 \%$ of control $(n=$ 6) with a concomitant increase in the RI from $1.3 \pm 0.1$ to $2.0 \pm 0.1(n=6 ; p<$ 0.05 ) (Fig. $8 E-G$ ). There was no significant change in RI during interleaved experiments with no spermine in the recording pipette $(n=6)$ (Fig. $8 F, G)$.

In addition, application of bpV (50 nM; $30 \mathrm{~min}$ ) increased surface GluR1 expression to $148 \pm 5.8 \%$ of control $(n=46 ; p<$ 0.01 ) (Fig. $8 H, I)$. BpV also altered the synaptic density of GluR1-containing AMPA receptors as colocalization between GluR1 and synapsin-1-positive sites was significantly enhanced from $31.8 \pm 2.6 \%$ to $43.2 \pm 3.9 \%(n=36 ; p<0.05)$; effects not significantly different $(p>0.05)$ to those of leptin $(49.2 \pm 6.0 \%$ colocalization; $n=27 ; p<0.01)$ in paired experiments. These data indicate that PTEN inhibition promotes an increase in the synaptic density of GluR1-containing AMPA receptors.

As PTEN inhibition results in increased PtdIns $(3,4,5) \mathrm{P}_{3}$ levels, we examined whether the increase in surface GluR1 labeling was associated with increased PtdIns $(3,4,5) \mathrm{P}_{3}$ levels. Treatment with bpV increased surface GluR1 labeling (146 $\pm 5.0 \%$ of control; $n=38 ; p<$ $0.01)$ and PtdIns $(3,4,5) \mathrm{P}_{3}$ staining $(154 \pm$ $6.2 \%$ of control; $n=38$; $p<0.05$ ) (Fig. $8 H, I)$. These effects of bpV were not significantly different to leptin as leptin resulted in increases to $152 \pm 6.9 \%(n=29$; $p<0.01: p>0.05$ compared with bpV) and $159 \pm 5.8 \%(n=29 ; p<0.01: p>$ 0.05 compared with bpV) in GluR1 and $\operatorname{PtdIns}(3,4,5) \mathrm{P}_{3}$ labeling, respectively. These data indicate that the effects of leptin are mimicked by PTEN inhibition. As leptin increases the synaptic density of GluR1 via PTEN inhibition, we determined whether PTEN inhibition altered the effects of leptin on GluR1 and PtdIns $(3,4,5) \mathrm{P}_{3}$ labeling. Treatment of hippocampal neurons with bpV occluded the effects of leptin such that GluR1 staining was $155 \pm 7.1 \%$ of control $(n=32 ; p<0.01)$ whereas $\operatorname{PtdIns}(3,4,5) \mathrm{P}_{3}$ labeling was $161 \pm 6.2 \%$ of control $(n=32$; $p<0.001$ ), in the combined presence of bpV and leptin (Fig. 8I). Exposure of hippocampal slices to leptin also occluded the effects of bpV such that leptin increased EPSC amplitude to $208 \pm 10 \%$ of baseline $(n=6)$, but subsequent application of bpV caused no sig-

\section{$\mathrm{H}$ Control}

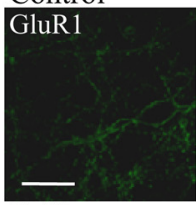

$\mathrm{BpV}$

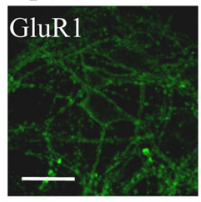

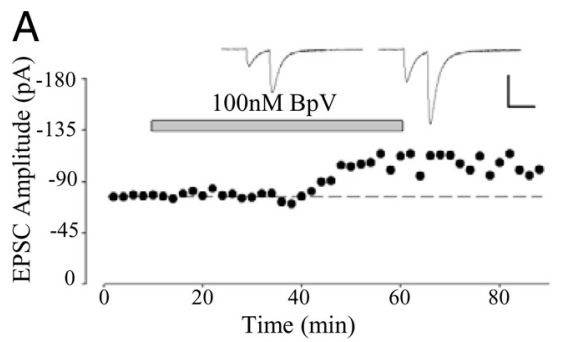
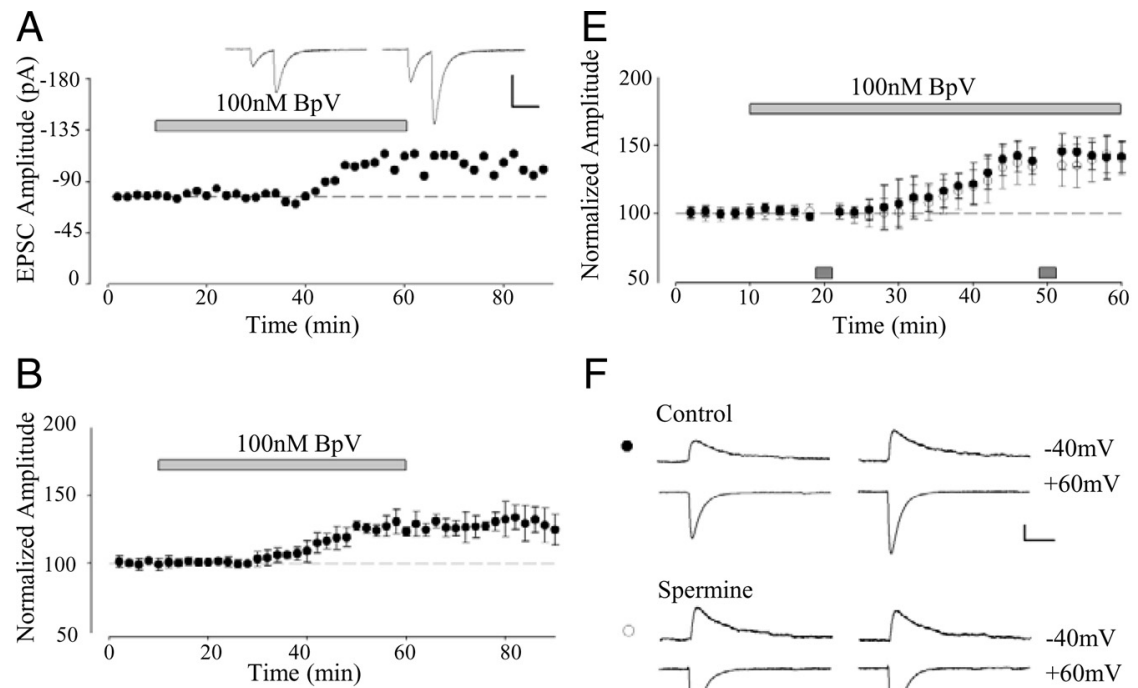

$\mathrm{F}$
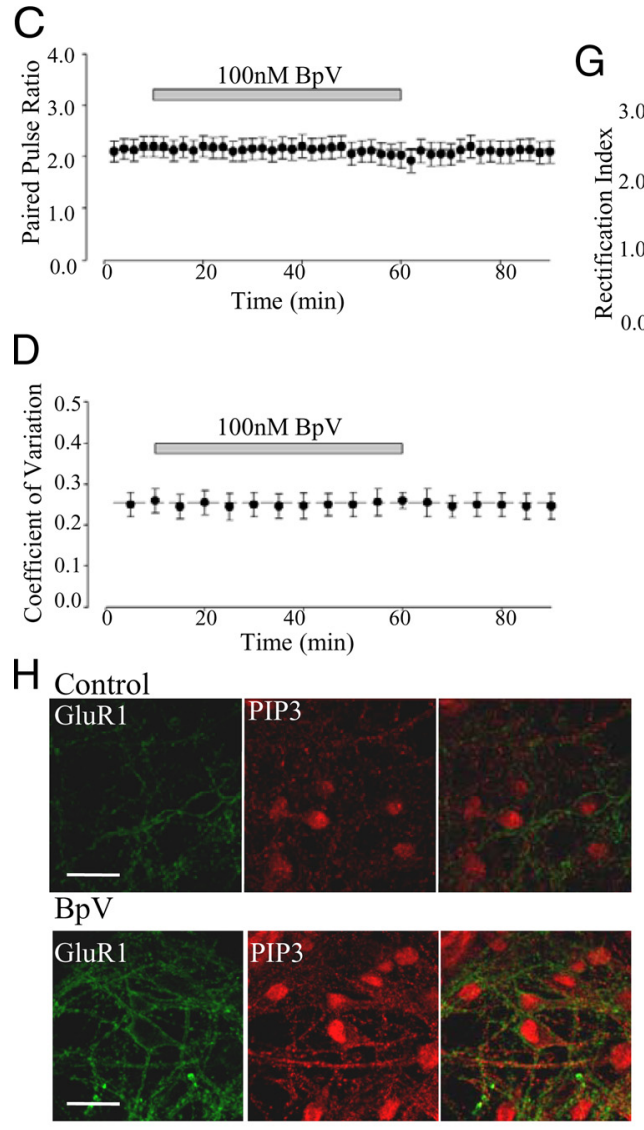

\section{G}
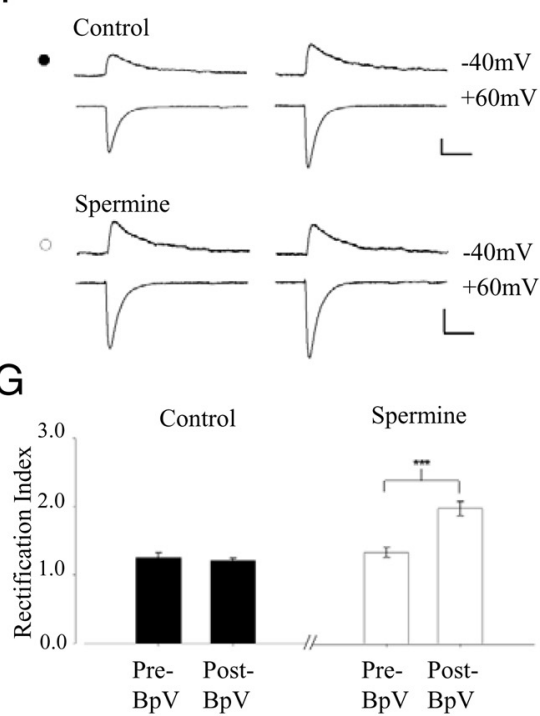

I

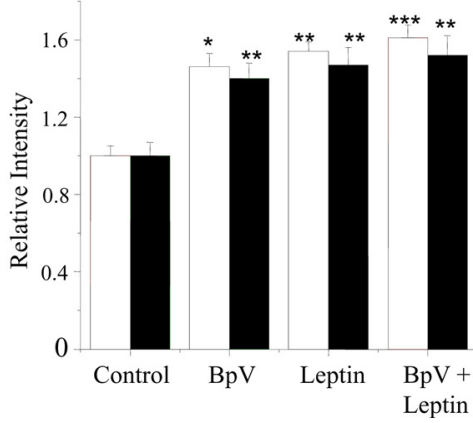

Figure 8. The effects of leptin are mimicked and occluded by inhibition of PTEN by bpV.A, Representative experiment showing that bpV potentiated EPSCs in hippocampal slices. Top, Example traces are shown for the times indicated. Calibration: $50 \mathrm{pA}, 50 \mathrm{~ms}$. B, Pooled data from all experiments. $\boldsymbol{C}, \boldsymbol{D}, \operatorname{PPR}(\boldsymbol{C})$ and $C V(\boldsymbol{D})$ show no significant change in response to bpV. E, Pooled data showing the effects of bpV using spermine-containing pipettes (open circles). Interleaved control experiments using control intracellular solution are also shown (filled circles). Cells were depolarized to $+40 \mathrm{mV}$ at the times indicated (gray bars). $\boldsymbol{F}$, Example EPSCs at $+40 \mathrm{mV}$ and $-60 \mathrm{mV}$ from an experiment in $\boldsymbol{E}$. Calibration: $50 \mathrm{pA}, 50 \mathrm{~ms}$. G, RI from the experiments in $\boldsymbol{E}$. $\boldsymbol{H}, \boldsymbol{I}, \mathrm{PTEN}$ inhibition increases surface GluR1 and Ptdlns $(3,4,5) \mathrm{P}_{3}$ levels and occludes the effects of leptin. $\boldsymbol{H}$, representative confocal images of surface GluR1 (green), Ptdlns $(3,4,5) \mathrm{P}_{3}$ (red) labeling and corresponding merged images in control conditions and after bpV exposure. bpV increased GluR1 and Ptdlns $(3,4,5) \mathrm{P}_{3}$ labeling. $I$, Pooled data of relative changes in Ptdlns $(3,4,5) \mathrm{P}_{3}$ (open bars) and surface GluR1 (filled bars) labeling in control conditions, after bpV or leptin treatment, and in the presence of bpV and leptin. Inhibition of PTEN mimicked and occluded the effects of leptin. nificant change in EPSC amplitude $(n=6 ; p>0.05)$. These data indicate that leptin increases the synaptic density of GluR1 via inhibition of PTEN as bpV not only mimicked but also occluded the effects of leptin. 


\section{Discussion}

Evidence is growing that leptin has widespread actions in the CNS. Several studies have implicated leptin in activity-dependent synaptic plasticity and hippocampal-dependent learning and memory (Harvey, 2007). AMPA receptor trafficking plays a pivotal role in regulating excitatory synaptic strength and numerous growth factors, and hormones modulate this process (Poo, 2001). In this study we provide compelling evidence that leptin regulates AMPA receptor trafficking in hippocampal neurons. Leptin preferentially increased the density of GluR1 as opposed to GluR2 subunits as leptin was $\sim 50$-fold more potent at increasing GluR1 surface expression in hippocampal cultures. Leptin also increased GluR1 but not GluR2 surface expression in adult hippocampal slices. Furthermore, leptin increased the synaptic density of GluR1 subunits, suggesting that leptin promotes delivery of GluR1-containing AMPA receptors to synapses. Indeed leptin enhanced the density of polyamine-sensitive EPSCs, indicating that leptin upregulates the synaptic expression of GluR2-lacking AMPA receptors. The differential effects of leptin on GluR1 versus GluR2 subunits displays parallels to the effects of BDNF and TNF- $\alpha$ on these subunits (Stellwagen and Malenka, 2006; Caldeira et al., 2007). Our findings also support the notion that distinct cellular mechanisms regulate the delivery of GluR1 and GluR2 to synapses (Passafaro et al., 2001; Shi et al., 2001). Our data demonstrate that blockade of exocytosis but not endocytosis attenuated the effects of leptin on surface GluR1 expression and synaptic transmission, indicating that leptin influences the synaptic density of AMPA receptors by promoting GluR1 exocytosis.

In contrast to the transient synaptic depression elicited by leptin in juvenile hippocampus (Shanley et al., 2001; Xu et al., 2008), leptin produced a persistent increase in excitatory synaptic strength in adult, suggesting that the effects of leptin on synaptic strength are developmentally regulated. However, leptin also transiently depresses excitatory synaptic transmission in 6- to 8-week mouse hippocampus (Xu et al., 2008), suggesting that modulation of excitatory synaptic transmission by leptin in adult hippocampus is age dependent, or alternatively that speciesdependent differences underlie the differential effects of leptin on synaptic transmission. We have shown that NMDA receptor activation is required for facilitation of hippocampal LTP and LTD induced by leptin (Shanley et al., 2001; Durakoglugil et al., 2005). Leptin-driven dendritic morphogenesis requires the synaptic activation of NMDA receptors (O'Malley et al., 2007). NMDA receptor activation also mediates delivery of GluR1 subunits to hippocampal synapses by leptin as leptin-dependent increases in surface GluR1 expression and EPSC amplitude were reduced by D-AP5. Moreover, the increase in synaptic strength by leptin was associated with an increase in NMDA receptor-mediated synaptic currents, and synaptic activation of NMDA receptors was required for the effects of leptin as leptin failed to increase synaptic transmission when stimulation was stopped. Similarly, the synaptic delivery of GluR1-containing AMPA receptors induced by tetanic stimulation or chemical induction of LTP requires synaptic activation of NMDA receptors (Passafaro et al., 2001; Shi et al., 2001; Man et al., 2003).

How the synaptic activation of NMDA receptors contributes to facilitation of synaptic transmission by leptin is not entirely clear. However, influx of $\mathrm{Ca}^{2+}$ via NMDA receptors is likely to play a significant role as chelation of $\mathrm{Ca}^{2+}$ ions with BAPTA blocked the effects of leptin, and we have shown previously that leptin has no effect on intracellular $\mathrm{Ca}^{2+}$ levels (Shanley et al., 2001). Recent studies indicate that CK2 is a downstream target of
NMDA receptors (Chung et al., 2004), and $\mathrm{Ca}^{2+}$-dependent increases in CK2 activity have also been reported after NMDA receptor-dependent LTP (Charriaut-Marlangue et al., 1991). Moreover, PTEN is phosphorylated by CK2 (Torres and Pulido, 2001), and our data indicate that CK2 activation is required for leptin-driven increases in GluR1 surface expression and synaptic transmission. Thus, it is feasible that leptin, via enhancing NMDA receptor activation, promotes an increase in CK2 activity, which in turn results in phosphorylation and subsequent inhibition of PTEN.

Our data indicate that the effects of leptin on GluR1 trafficking involve an increase in $\operatorname{PtdIns}(3,4,5) \mathrm{P}_{3}$ levels secondary to PTEN inhibition as the effects of leptin on surface GluR1 staining were associated with increased PtdIns $(3,4,5) \mathrm{P}_{3}$ levels and elevations in PtdIns $(3,4,5) \mathrm{P}_{3}$ levels occurred before altered GluR1 trafficking. In agreement with previous studies (Man et al., 2003), inhibitors of PI 3-kinase attenuated the effects of leptin on surface GluR1 and PtdIns $(3,4,5) \mathrm{P}_{3}$ levels, consistent with PI 3-kinasedependent signaling underlying these effects. However, our studies indicate that leptin trafficking of GluR1 to synapses is mediated by a novel mechanism involving PTEN inhibition. Leptin increased phosphorylation of PTEN, an effect associated with an increase in PtdIns $(3,4,5) \mathrm{P}_{3}$ levels. Moreover, inhibition of PTEN mimicked and occluded leptin-induced trafficking of GluR1 to hippocampal synapses and facilitation of excitatory synaptic transmission. The role of PTEN inhibition in hippocampal leptin-driven signaling displays parallels to the role of PTEN in the activation of hypothalamic $\mathrm{K}_{\mathrm{ATP}}$ channels by leptin (Ning et al., 2006; Plum et al., 2006). Indeed, genetic inactivation of hypothalamic PTEN elevates PtdIns $(3,4,5) \mathrm{P}_{3}$-dependent signaling which is pivotal for $\mathrm{K}_{\mathrm{ATP}}$ channel activation by leptin (Plum et al., 2006).

In most cells PTEN is constitutively active and thereby influences the basal levels of PtdIns $(3,4,5) \mathrm{P}_{3}$. Transgenic mouse studies indicate that regulation of PTEN occurs primarily via its inhibition or reduced cellular expression which in turn enhances PI 3-kinase-dependent signaling. Our studies show that leptin regulates PTEN by increasing its phosphorylation which is likely to result in inhibition of its phosphatase activity. Our data also indicate that the cellular distribution of PTEN was altered after phosphorylation as the phosphorylated form of PTEN localized to the Golgi apparatus. In agreement with these findings, studies in non-neuronal cells have shown that phosphorylation of PTEN alters its subcellular localization (Leslie et al., 2008). As PTEN needs to associate with the plasma membrane for its constitutive activity, it is likely that translocation of PTEN to the Golgi apparatus limits its ability to antagonize PI 3-kinase-dependent signaling. However, it is not clear whether PTEN redistribution to the Golgi directly influences AMPA receptor trafficking and excitatory synaptic function. During exocytosis, membrane proteins can be delivered directly from the trans-Golgi network to the plasma membrane. The trans-Golgi network also regulates the synaptic delivery of GluR1-containing AMPA receptors during synaptic plasticity (Gerges et al., 2004). Thus, specific targeting of inactive phosphorylated PTEN to the Golgi may result in highly localized elevations in $\operatorname{PtdIns}(3,4,5) \mathrm{P}_{3}$ levels close to this subcellular compartment. However, it is not clear how elevations in PtdIns $(3,4,5) \mathrm{P}_{3}$ levels influence delivery of AMPA receptors to synapses. As PtdIns $(3,4,5) \mathrm{P}_{3}$ modifies the activity of numerous signaling molecules, including phosphoinositide-dependent kinases and guanine nucleotide exchange factors (GEFs; Cantley, 2002), one or more of these downstream targets may play a role in this process. One potential target for $\operatorname{PtdIns}(3,4,5) \mathrm{P}_{3}$ is $\mathrm{Akt}$, a 
kinase that promotes phosphorylation and inhibition of glycogen synthase kinase-3 (GSK-3). Indeed, nerve growth factor phosphorylates and inactivates PTEN, leading to GSK-3 $\beta$ inhibition and axonal outgrowth (Arevalo and Rodríguez-Tébar, 2006). GSK-3 $\beta$ is also implicated in AMPA receptor trafficking, as AMPA receptor insertion after chemical induction of hippocampal LTP is associated with increased PI 3-kinase/Aktdriven inhibition of GSK-3 $\beta$ (Peineau et al., 2007). Alterations in PtdIns $(3,4,5) \mathrm{P}_{3}$ levels may promote structural rearrangement of the actin cytoskeleton which in turn influences the synaptic density of AMPA receptors (Zhou et al., 2001). Indeed, GEFs control the activity and function of Rho GTPases, a family of proteins that regulate the actin cytoskeleton. Moreover, one particular GEF, kalirin-7, associates with and controls the synaptic expression of GluR1-containing AMPA receptors (Xie et al., 2007).

Most evidence points to altering the phosphorylation status of PTEN as the main mechanism for regulating PTEN function. Changes in PTEN phosphorylation not only regulate its activity, but also influence its association with PDZ domains from other regulatory molecules, including the scaffolding proteins MAGI-2 and synapse-associated protein-97 (SAP97; Valiente et al., 2005; Vazquez et al., 2001). As SAP97 is a membrane-associated guanylate kinase (MAGUK) that regulates the insertion and synaptic localization of GluR1-containing AMPA receptors (Rumbaugh et al., 2003), leptin, by promoting PTEN phosphorylation, may alter PTEN/SAP-97 interactions, which influences GluR1 trafficking. MAGI-2 is also linked to AMPA receptor trafficking as it interacts with transmembrane AMPA receptor regulating proteins (TARPS), and it links TARP/AMPA receptor complexes to other postsynaptic molecules (Deng et al., 2006). MAGI-2 binding to PTEN enhances PTEN-dependent suppression of PI 3-kinase/Akt activation (Wu et al., 2000), whereas PTEN phosphorylation causes a conformational change that reduces MAGI-2 binding to PTEN (Valiente et al., 2005). Thus, our data are consistent with leptin promoting PTEN phosphorylation which would reduce MAGI-2/PTEN interactions and thereby enhance PI 3-kinase/Akt signaling and AMPA receptor trafficking.

Leptin is a circulating hormone that is transported to most brain regions via transport across the blood-brain barrier. Leptin mRNA and protein have been detected in several brain regions, including the hippocampus (Morash et al., 1999), and recent studies have shown leptin production by the brain (Eikelis et al., 2007). Thus, the concentration of leptin reaching hippocampal synapses is likely to be derived from that released locally as well as from peripheral sources. Several studies indicate that leptin markedly influences the cellular events underlying hippocampaldependent learning and memory (Harvey, 2007). Indeed leptin facilitates hippocampal LTP via enhancing NMDA receptor function, and it promotes rapid changes in hippocampal dendritic morphology and synaptic density. The ability of leptin to rapidly alter the synaptic density of GluR1-containing AMPA receptors provides additional evidence in support of a role for leptin in regulating hippocampal synaptic plasticity.

Evidence is accumulating that cognitive deficits occur in leptin-insensitive rodents ( $\mathrm{Li}$ et al., 2002) and are associated with obesity-related diseases like type II diabetes. Recent studies have linked altered leptin levels to neurodegenerative disorders as patients with Alzheimer disease display attenuated leptin levels (Power et al., 2001). Studies in transgenic mice overexpressing amyloid $\beta$ indicate that leptin significantly reduces amyloid $\beta$ levels. As obesity and related disorders are thought to be a consequence of blood-brain barrier resistance to leptin, resistance to this hormone may contribute to cognitive deficits in diabetics and in neurodegenerative disorders. Thus, the ability of leptin to promote changes in the efficacy of excitatory synaptic transmission via rapid trafficking of AMPA receptor may be crucial for its role not only in normal CNS function but also in neurological disorders associated with leptin resistance or insensitivity.

\section{References}

Anderson WW, Collingridge GL (2007) Capabilities of the WinLTP data acquisition program extending beyond basic LTP experimental functions. J Neurosci Methods 162:346-356.

Arevalo MA, Rodríguez-Tébar A (2006) Activation of casein kinase II and inhibition of phosphatase and tensin homologue deleted on chromosome 10 phosphatase by nerve growth factor/p75NTR inhibit glycogen synthase kinase-3beta and stimulate axonal growth. Mol Biol Cell 17:33693377.

Bliss TV, Collingridge GL (1993) A synaptic model of memory: long-term potentiation in the hippocampus. Nature 361:31-39.

Caldeira MV, Melo CV, Pereira DB, Carvalho R, Correia SS, Backos DS, Carvalho AL, Esteban JA, Duarte CB (2007) Brain-derived neurotrophic factor regulates the expression and synaptic delivery of alpha-amino3-hydroxy-5-methyl-4-isoxazole propionic acid receptor subunits in hippocampal neurons. J Biol Chem 282:12619-12628.

Cantley LC (2002) The phosphoinositide 3-kinase pathway. Science 296:1655-1657

Caro JF, Sinha MK, Kolaczynski JW, Zhang PL, Considine RV (1996) Leptin: the tale of an obesity gene. Diabetes 45:1455-1462.

Charriaut-Marlangue C, Otani S, Creuzet C, Ben-Ari Y, Loeb J (1991) Rapid activation of hippocampal casein kinase II during long-term potentiation. Proc Natl Acad Sci U S A 88:10232-10236.

Chung HJ, Huang YH, Lau LF, Huganir RL (2004) Regulation of the NMDA receptor complex and trafficking by activity-dependent phosphorylation of the NR2B subunit PDZ ligand. J Neurosci 24:10248-10259.

Collingridge GL, Kehl SJ, McLennan H (1983) Excitatory amino acids in synaptic transmission in the Schaffer collateral-commissural pathway of the rat hippocampus. J Physiol 334:33-46.

Collingridge GL, Isaac JT, Wang YT (2004) Receptor trafficking and synaptic plasticity. Nat Rev Neurosci 5:952-962.

Coutts AA, Anavi-Goffer S, Ross RA, MacEwan DJ, Mackie K, Pertwee RG, Irving AJ (2001) Agonist-induced internalization and trafficking of cannabinoid CB1 receptors in hippocampal neurons. J Neurosci 21:2425-2433.

Deng F, Price MG, Davis CF, Mori M, Burgess DL (2006) Stargazin and other transmembrane AMPA receptor regulating proteins interact with synaptic scaffolding protein MAGI-2 in brain. J Neurosci 26:7875-7884.

Downes CP, Ross S, Maccario H, Perera N, Davidson L, Leslie NR (2007) Stimulation of PI 3-kinase signaling via inhibition of the tumor suppressor phosphatase, PTEN. Adv Enzyme Regul 47:184-194.

Durakoglugil M, Irving AJ, Harvey J (2005) Leptin induces a novel form of NMDA receptor-dependent long-term depression. J Neurochem 95:396-405.

Eikelis N, Wiesner G, Lambert G, Esler M (2007) Brain leptin resistance in human obesity revisited. Regul Pept 139:45-51.

Gerges NZ, Backos DS, Esteban JA (2004) Local control of AMPA receptor trafficking at the postsynaptic terminal by a small GTPase of the Rab family. J Biol Chem 279:43870-43878.

Harvey J (2007) Leptin regulation of neuronal excitability and cognitive function. Curr Opin Pharmacol 7:643-647.

Koh DS, Burnashev N, Jonas P (1995) Block of native Ca(2+)-permeable AMPA receptors in rat brain by intracellular polyamines generates double rectification. J Physiol 486:305-312.

Leslie NR, Batty IH, Maccario H, Davidson L, Downes CP (2008) Understanding PTEN regulation: PIP2, polarity and protein stability. Oncogene 27:5464-5476.

Li XL, Aou S, Oomura Y, Hori N, Fukunaga K, Hori T (2002) Impairment of long-term potentiation and spatial memory in leptin receptor-deficient rodents. Neurosci 113:607-615.

Maccario H, Perera NM, Davidson L, Downes CP, Leslie NR (2007) PTEN is destabilized by phosphorylation on Thr366. Biochem J 405:439-444.

Maehama T, Dixon JE (1998) The tumor suppressor, PTEN/MMAC1, dephosphorylates the lipid second messenger, phosphatidylinositol 3,4,5trisphosphate. J Biol Chem 273:13375-13378. 
Man HY, Wang Q, Lu WY, Ju W, Ahmadian G, Liu L, D’Souza S, Wong TP, Taghibiglou C, Lu J, Becker LE, Pei L, Liu F, Wymann MP, MacDonald JF, Wang YT (2003) Activation of PI3-kinase is required for AMPA receptor insertion during LTP of mEPSCs in cultured hippocampal neurons. Neuron 38:611-624.

Morash B, Li A, Murphy PR, Wilkinson M, Ur E (1999) Leptin gene expression in the brain and pituitary gland. Endocrinology 140:5995-5998.

Moult PR, Milojkovic B, Harvey J (2009) Leptin reverses long-term potentiation at hippocampal CA1 synapses. J Neurochem 108:685-696.

Nicoll RA, Malenka RC (1999) Expression mechanisms underlying NMDA receptor-dependent long-term potentiation. Ann N Y Acad Sci 868:515-525.

Ning K, Miller LC, Laidlaw HA, Burgess LA, Perera NM, Downes CP, Leslie NR, Ashford ML (2006) A novel leptin signalling pathway via PTEN inhibition in hypothalamic cell lines and pancreatic beta-cells. EMBO J 25:2377-2387.

O’Malley D, MacDonald N, Mizielinska S, Connolly CN, Irving AJ, Harvey J (2007) Leptin promotes rapid dynamic changes in hippocampal dendritic morphology. Mol Cell Neurosci 35:559-572.

Pagano MA, Meggio F, Ruzzene M, Andrzejewska M, Kazimierczuk Z, Pinna LA (2004) 2-Dimethylamino-4,5,6,7-tetrabromo-1H-benzimidazole: a novel powerful and selective inhibitor of protein kinase CK2. Biochem Biophys Res Commun 321:1040-1044.

Passafaro M, Piëch V, Sheng M (2001) Subunit-specific temporal and spatial patterns of AMPA receptor exocytosis in hippocampal neurons. Nat Neurosci 4:917-926.

Peineau S, Taghibiglou C, Bradley C, Wong TP, Liu L, Lu J, Lo E, Wu D, Saule E, Bouschet T, Matthews P, Isaac JT, Bortolotto ZA, Wang YT, Collingridge GL (2007) LTP inhibits LTD in the hippocampus via regulation of GSK3beta. Neuron 53:703-717.

Pickard L, Noël J, Duckworth JK, Fitzjohn SM, Henley JM, Collingridge GL, Molnar E (2001) Transient synaptic activation of NMDA receptors leads to the insertion of native AMPA receptors at hippocampal neuronal plasma membranes. Neuropharmacol 41:700-713.

Plum L, Ma X, Hampel B, Balthasar N, Coppari R, Münzberg H, Shanabrough M, Burdakov D, Rother E, Janoschek R, Alber J, Belgardt BF, Koch L, Seibler J, Schwenk F, Fekete C, Suzuki A, Mak TW, Krone W, Horvath TL, Ashcroft FM, Brüning JC (2006) Enhanced PIP3 signaling in POMC neurons causes KATP channel activation and leads to dietsensitive obesity. J Clin Invest 116:1886-1901.

Poo MM (2001) Neurotrophins as synaptic modulators. Nat Rev Neurosci 2:24-32.

Power DA, Noel J, Collins R, O’Neill D (2001) Circulating leptin levels and weight loss in Alzheimer's disease patients. Dement Geriatr Cogn Disord $12: 167-170$.

Rumbaugh G, Sia GM, Garner CC, Huganir RL (2003) Synapse-associated protein-97 isoform-specific regulation of surface AMPA receptors and synaptic function in cultured neurons. J Neurosci 23:4567-4576.

Schmid AC, Byrne RD, Vilar R, Woscholski R (2004) Bisperoxovanadium compounds are potent PTEN inhibitors. FEBS Lett 566:35-38.

Shanley LJ, Irving AJ, Harvey J (2001) Leptin enhances NMDA receptor function and modulates hippocampal synaptic plasticity. J Neurosci 21:RC186.

Shi S, Hayashi Y, Esteban JA, Malinow R (2001) Subunit-specific rules governing AMPA receptor trafficking to synapses in hippocampal pyramidal neurons. Cell 105:331-343.

Spiegelman BM, Flier JS (2001) Obesity and the regulation of energy balance. Cell 104:531-543.

Stellwagen D, Malenka RC (2006) Synaptic scaling mediated by glial TNFalpha. Nature 440:1054-1059.

Thomas-Crusells J, Vieira A, Saarma M, Rivera C (2003) A novel method for monitoring surface membrane trafficking on hippocampal acute slice preparation. J Neurosci Methods 125:159-166.

Torres J, Pulido R (2001) The tumor suppressor PTEN is phosphorylated by the protein kinase CK2 at its C terminus. Implications for PTEN stability to proteasome-mediated degradation. J Biol Chem 276:993-998.

Valiente M, Andrés-Pons A, Gomar B, Torres J, Gil A, Tapparel C, Antonarakis SE, Pulido R (2005) Binding of PTEN to specific PDZ domains contributes to PTEN protein stability and phosphorylation by microtubule-associated serine/threonine kinases. J Biol Chem 280:28936-28943.

Vazquez F, Grossman SR, Takahashi Y, Rokas MV, Nakamura N, Sellers WR (2001) Phosphorylation of the PTEN tail acts as an inhibitory switch by preventing its recruitment into a protein complex. J Biol Chem 276:48627-48630.

Wayner MJ, Armstrong DL, Phelix CF, Oomura Y (2004) Orexin-A (Hypocretin-1) and leptin enhance LTP in the dentate gyrus of rats in vivo. Peptides 25:991-996.

Wu X, Hepner K, Castelino-Prabhu S, Do D, Kaye MB, Yuan XJ, Wood J, Ross C, Sawyers CL, Whang YE (2000) Evidence for regulation of the PTEN tumor suppressor by a membrane-localized multi-PDZ domain containing scaffold protein MAGI-2. Proc Natl Acad Sci U S A 97:4233-4238.

Xie Z, Srivastava DP, Photowala H, Kai L, Cahill ME, Woolfrey KM, Shum CY, Surmeier DJ, Penzes P (2007) Kalirin-7 controls activity-dependent structural and functional plasticity of dendritic spines. Neuron 56: 640-656.

Xu L, Rensing N, Yang XF, Zhang HX, Thio LL, Rothman SM, Weisenfeld AE, Wong M, Yamada KA (2008) Leptin inhibits 4-aminopyridine- and pentylenetetrazole-induced seizures and AMPAR-mediated synaptic transmission in rodents. J Clin Invest 118:272-280.

Zhou Q, Xiao M, Nicoll RA (2001) Contribution of cytoskeleton to the internalization of AMPA receptors. Proc Natl Acad Sci U S A 30:12611266. 